This is an accepted manuscript. Please cite as: Singh, M. (forthcoming) Magic, explanations, and evil: On the origins and design of witches and sorcerers. Current Anthropology.

\title{
Magic, explanations, and evil On the origins and design of witches and sorcerers
}

\author{
Manvir Singh \\ Department of Human Evolutionary Biology, Harvard University
}

13 March 2020

\begin{abstract}
In nearly every documented society, people believe that some misfortunes are caused by malicious group mates using magic or supernatural powers. Here I report cross-cultural patterns in these beliefs and propose a theory to explain them. Using the newly-created Mystical Harm Survey, I show that several conceptions of malicious mystical practitioners recur around the world, including sorcerers (who use learned spells), possessors of the evil eye (who transmit injury through their stares and words), and witches (who possess superpowers, pose existential threats, and engage in morally abhorrent acts). I argue that these beliefs develop from three cultural selective processes: a selection for intuitive magic, a selection for plausible explanations of impactful misfortune, and a selection for demonizing myths that justify mistreatment.

Separately, these selective schemes produce traditions as diverse as shamanism, conspiracy theories, and campaigns against heretics - but around the world, they jointly give rise to the odious and feared witch. I use the tripartite theory to explain the forms of beliefs in mystical harm and outline ten predictions for how shifting conditions should affect those conceptions. Societally-corrosive beliefs can persist when they are intuitively appealing or they serve some believers' agendas.
\end{abstract}




\section{ON THE ORIGINS AND DESIGN OF WITCHES AND SORCERERS}

"I fear them more than anything else," said Don Talayesva ${ }^{1}$ about witches. By then, the Hopi man suspected his grandmother, grandfather, and in-laws of using dark magic against him.

\section{Introduction}

Beliefs in witches and sorcerers are disturbing and calamitous. Sterility, illness, death, rainstorms, burnt-down houses, bald spots, attacks from wild animals, lost foot races, lost reindeer races, the puzzling behavior of a friend or spouse - the enigmatic, the impactful, the bothersome - all can spark suspicions of neighbors using magic and dark powers; all can precipitate violence. The suspects are sometimes normal humans, learned in dark magic, but other times, they are rumored to be odious and other. They devour babies, fornicate with their menstruating mothers, and use human skulls for sports. They become bats and black panthers, house pythons in their stomachs, and direct menageries of attendant nightbirds. They plot the destruction of families and then dance in orgiastic night-fests. ${ }^{2}$

Humans in nearly every documented believe that some illnesses and hardships are the work of envious or malignant group mates. Hutton $(2004 ; 2017)$ reviewed ethnographies from three hundred non-European societies and documented pervasive beliefs in sorcerers, witches, the evil eye, and aggressive shamans. Of the 60 societies in the Probability Sample File of the Human Relations Area Files - a pseudo-random sample of well-documented human societies 59 believed in some form of human-induced mystical harm, the only exception being the Kogi of Colombia $^{3}$ (sect. 2). European societies have historically held similar beliefs, embodied in the Roman strix (Oliphant 1913; Oliphant 1914), the Saxon striga (Cohn 1976), and most famously, the witches of the Great European Witch Hunt (Cohn 1976), and colonial New England (Karlsen 1987).

Beliefs about harmful practitioners are profoundly similar across vastly distant societies (Needham 1978; Kluckhohn 1959). The European witches of the late modern period were said to eat human flesh, engage in obscene activities, and assemble in conspiratorial, orgiastic

\footnotetext{
${ }^{1}$ The quotation comes from autobiography of Don Talayesva (Talayesva and Simmons 1942:379).

${ }^{2}$ The quotes by Don Talayesva (opening) and the Santal guru Kolean Haram (section 3) demonstrate that these beliefs are disturbing. The destruction mentioned in section 3 demonstrates that they're calamitous. Table 2 and section 6.2 .1 describe the events that trigger suspicions of mystical harm. Table 3 features examples of animal transformations and attendants. Yamba witches were said to devour children (Gufler 1999), Apache witches had sex with menstruating family members (Basso 1969), Akan witches used human skulls for soccer (Debrunner 1961), and Santal witches met naked in nighttime assemblies, danced, and copulated with their spirit familiars (Archer 1974). Nyakyusa witches had pythons in their bellies (Wilson 1951).

${ }^{3}$ The ethnographic texts included in eHRAF did not describe mystical harm beliefs in two PSF societies: the Koreans and the Kogi. But researchers elsewhere have reported sorcery beliefs in Korea (Walraven 1980), so their omission seems due to ethnographers underreporting the topic. Meanwhile, ReichelDolmatoff $(1997: 141 ; 1976: 286)$ explicitly stressed the absence of beliefs in mystical harm among the Kogi. Nevertheless, in describing Kogi lineages, he made a vague comment suggesting that people do in fact believe in mean-spirited, uncanny harm: "Both groups, the Hukúkui as well as the Mitamdú, are further regarded as vaguely dangerous and endowed with rather evil powers" (Reichel-Dolmatoff 1997:250).
} 


\section{ON THE ORIGINS AND DESIGN OF WITCHES AND SORCERERS}

nighttime gatherings (Cohn 1976). Similar behaviors were suspected of witches among the Yamba of Cameroon (Gufler 1999), the Santal of South Asia (Archer 1984), and the Navajo of the American Southwest (Kluckhohn 1944), among many other societies (Hutton 2017; Mair 1969; see sect. 2). And just as people worldwide believe in sensational and atrocious witches, they also often suspect that sickness and death are the work of ordinary people secretly practicing dark magic (e.g., Trobriand Islanders: Malinowski 1922; Tswana: Schapera 1952; Niimíipuu: Walker, Jr. 1967).

In this paper, I refer to people believed to use magic or supernatural powers to injure others as practitioners of mystical harm ${ }^{4}$. This term is broad, including, for example, beliefs about werewolves, abhorrent witches, people whose stares transmit illness, and neighbors who use voodoo dolls in secret. Magic refers to occult methods with instrumental ends, such as spells, curses, rites, manipulated objects, and everyday superstitions. Magic can be used ${ }^{5}$ to produce socially-justified ends, such as healing people or succeeding in gambling, as well as less acceptable objectives, such as inducing illness. I use refer to harmful magic as sorcery. Methods of sorcery include cursing, stabbing voodoo dolls, and placing charmed poisons in people's paths.

Sorcerers are people who use magic for malicious ends - that is, people who use sorcery. Witches, on the other hand, exhibit up to three sets of characteristics: (1) They are existentially threatening, (2) they have supernatural powers, and (3) they are morally repugnant. Some practitioners qualify as both sorcerers and witches, such as those believed to both use magic and engage in activities like graveyard conspiracies and cannibalism. I justify these definitions in section 2 .

The ubiquity of mystical harm beliefs and their striking similarities raise two basic questions:

1. Why do humans believe in mystical harm?

2. Why do those beliefs take the form that they do?

This paper advances a tripartite theory to answer those questions. I propose that beliefs in mystical harm, and beliefs about who orchestrates it, are the result of three cultural selective processes:

1. Selection for intuitive magic. As people try to influence others' misfortune, they selectively retain intuitive magic, producing compelling spells and charms for harming others. This produces intuitive harmful magic, but more relevantly, it convinces people that sorcery works and that other group members practice it.

2. Selection for plausible explanations of misfortune. People look for explanations for why things go wrong. When they feel threatened, they suspect distrusted group mates; when they believe in sorcery, it provides a straightforward explanation for how a

\footnotetext{
${ }^{4}$ I choose the term mystical to refer to harm that is transmitted either through magical means (e.g., spells, buried poisons, voodoo dolls) or supernatural powers (e.g., transforming into an animal and attacking someone, inflicting misfortune through an inadvertent envious stare). This usage follows Evans-Pritchard (1937), who contrasted mystical causation with natural causation, and Needham (1978:26), who defined a witch as "someone who causes harm to others by mystical means", corresponding closely with my term practitioner of mystical harm.

${ }^{5}$ Whenever I refer to the effects of magic (e.g., producing illness) or the features of a malicious practitioner (e.g., flying and eating corpses), I refer to beliefs about those traditions rather than actual consequences or traits.
} 


\section{ON THE ORIGINS AND DESIGN OF WITCHES AND SORCERERS}

distrusted rival harmed them from afar. Over time, iteratively searching for plausible explanations shapes beliefs about sorcerers to become increasingly compelling, although the same process can produce explanations that do not include sorcery, including beliefs about werewolves, the evil eye, and conspiratorial governments.

3. Selection for demonizing narratives. Actors bent on eliminating rivals devise demonizing myths to justify their rivals' mistreatment. These campaigns often target and transform malicious practitioners, both because people suspect that malicious practitioners transmit harm and because individuals accused of mystical harm are easily demonized and abused.

On their own, these three processes produce beliefs and practices as varied as gambling superstitions, conspiracy theories, and vitriolic campaigns against heretics, but in societies around the world, they combine to produce the archetypal, odious image of the witch.

\section{Cross-cultural patterns}

Researchers struggle over whether beliefs about harmful practitioners are similar across cultures. Many have emphasized commonalities (e.g., Mair 1969; Kluckhohn 1959), but others have criticized drawing these comparisons, one scholar concluding that "anthropologists have committed a possibly grave error in using the same term [witchcraft] for other cultures" (Crick 1973:18).

The most important effort in documenting cross-cultural patterns in these beliefs was conducted by Hutton (2017; see also Hutton 2004). Hutton reviewed ethnographies in three hundred extra-European societies and identified five characteristics that malicious magicians around the world share with the early modern European conception of the witch. Namely, they tend to (1) cause harm using non-physical, "uncanny" methods, (2) represent internal threats to their communities, (3) gain their abilities through training or inheritance, (4) have qualities that incite horror and loathing, and (5) give rise to strategies of resistance, including counterspells and murderous campaigns. Hutton also reviewed, among other things, similarities in witches' heinous activities and the social conditions that inspire violence towards suspected malicious practitioners.

Hutton's project was ambitious, but he sampled societies opportunistically, risking the overrepresentation of peculiar beliefs. He also chose not to systematically code traits, such as how frequently practitioners are believed to kill people or associate with animals. These limitations prevented him from drawing strong inferences about how these beliefs compare around the world.

I designed the Mystical Harm Survey (MHS) to systematically capture beliefs about mystical harm in a representative sample of the world's societies. The dataset covers the 60 societies of the Probability Sample File of the Human Relations Area Files, a pseudo-random sample of well-documented cultures that were selected to make inferences about humanity more generally (see the Supplementary Materials for more details). The full dataset is available at osf.io/492mj and includes beliefs about 103 malicious practitioners (or practices) from 58 societies. The analyses reported here exclude leaders (e.g., elders, chiefs, senior lineages) and public magicians (e.g., shamans, priests), because these practitioners are public, institutionalized classes who advertise and perform their powers rather than simply being conceptions of group 


\section{ON THE ORIGINS AND DESIGN OF WITCHES AND SORCERERS}

mates causing misfortune (including leaders and magicians produces nearly identical results; compare Supplementary Table 2 with Supplementary Table 4). ${ }^{6}$

I used Principal Components Analysis to reduce the 49 raw variables in the Mystical Harm Survey (e.g., does a practitioner consume flesh? do they cause economic harm?) to two derived variables (or principal components) ${ }^{7}$, shown in Figure 1 (see Supplementary Materials for details). This method exposes the axes along which practitioners vary the most and, thus, the cross-cultural structure of these beliefs. Both of the derived variables are interpretable: The first dimension represents how witchy malefactors are; the second distinguishes sorcerers, as classically understood, from the evil eye.

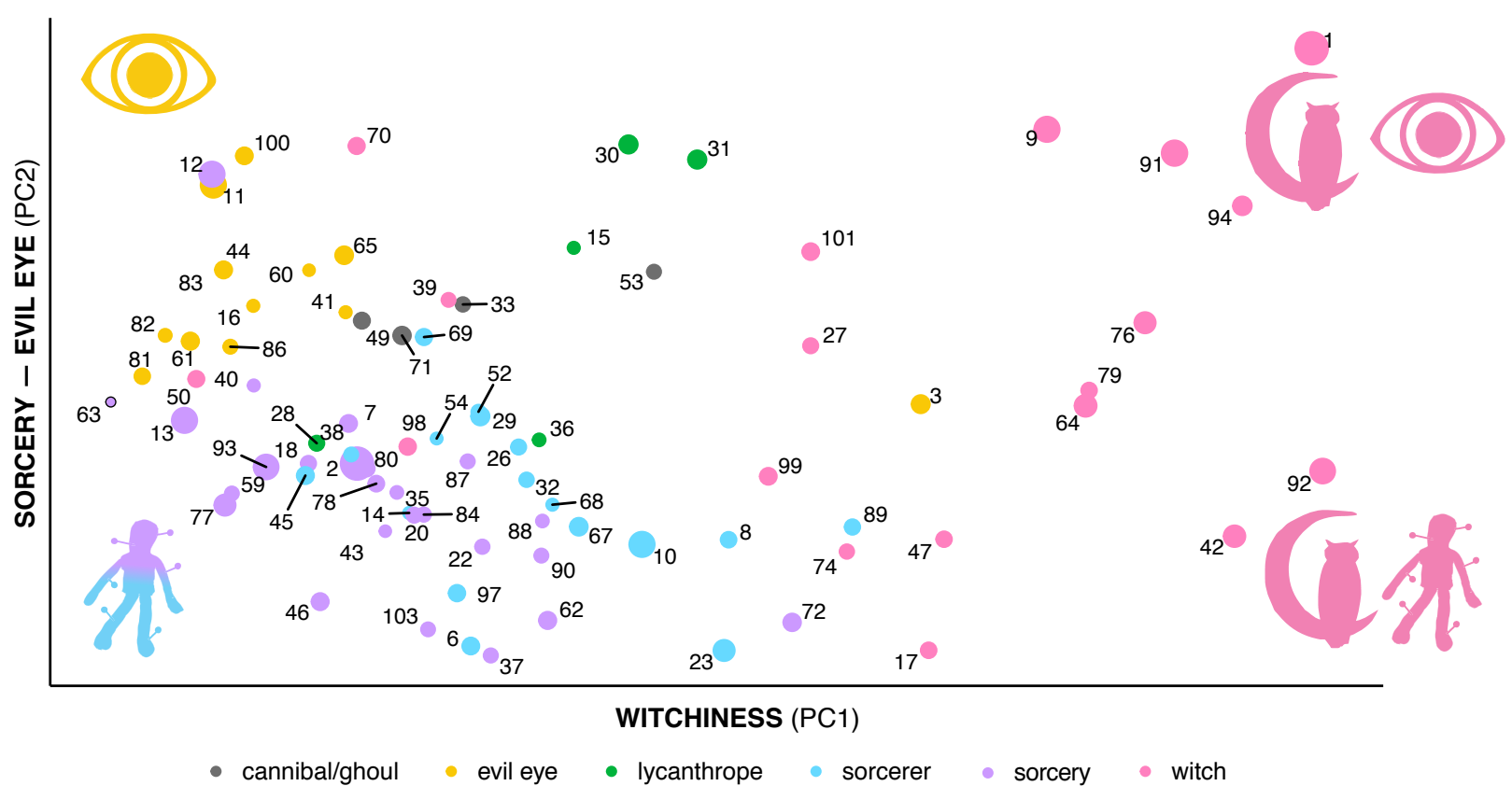

Figure 1. Results of logistic PCA showing practitioners of mystical harm. A single point represents a belief about a practitioner in a society (such as the Trobriand flying witch or the Amhara evil eye); the accompany numbers refer to the unique practitioner ID numbers (see Supplementary Table 1). The points are colored according to the terms used by the ethnographer(s) who described them. They are scaled according to the number of paragraphs coded in that society, ranging from 1 paragraph (practitioner 63) to 1,976 (practitioners 1 and 2). The images refer to the features that characterize a given quadrant: eye = evil eye (unintentional harm through stares or words); effigy = sorcery (learned magic); owl = witchiness (superhuman abilities, moral abhorrence, threat).

${ }^{6}$ Hereafter, I refer to this restricted dataset as the MHS and to the dataset including leaders and public magicians as the expanded MHS.

${ }^{7}$ There are two reasons to report a two-factor solution. First, a scree plot (Supplementary Figure 1) shows a dramatic change in slope (or elbow) at the third component; after the second component, the additional dimensions explain equivalent and smaller proportions of variance. Second, the third component is uninterpretable (see Supplementary Table 3). The first and second components explain $23.1 \%$ and $16.8 \%$ of the total variance, respectively $(39.9 \%$ in total). 


\section{ON THE ORIGINS AND DESIGN OF WITCHES AND SORCERERS}

Practitioners high on the first variable (PC1) are witches. ${ }^{8}$ They are believed to kill people, cause illness, eat human flesh, desecrate corpses, use magic, fly, turn invisible, commit atrocities at night and in the nude, congregate in secretive meetings, transform into animals or use them as familiars, and engage in obscenities like incest and nymphomania; shamans and other magicians are often suspected of being witches (see Supplementary Table 2 for loadings). Practitioners low on this dimension lack these qualities. Contrary to many writers' impressions (e.g., Chaudhuri 2012; Mace et al. 2018; Sanders 1995), I did not find strong evidence that witches are more frequently women than men.

The second derived variable (PC2) separates everyday sorcerers from the evil eye. Practitioners low on PC2 use harmful magic, including spells, voodoo dolls, and magical poisons. They attack their neighbors and family members but sometimes target out-group individuals as well. Ethnographers often state that anyone can qualify as one of these practitioners, although men and public magicians are suspected more often. Practitioners high on PC2, in contrast, tend to possess the evil eye or blasting word: They harm people through their stares and comments, often inadvertently. Their powers derive from physiological differences, such as special eyes, rather than from learning specific methods or rites.

A surprising finding is that practitioners high on PC2 also tend to fly and eat human flesh. But this is less characteristic of the evil eye and more a feature of cannibals, ghouls, and lycanthropes (humans who transform into animals). In fact, no practitioner labeled "evil eye" by an ethnographer was said to fly or consume human flesh. Cannibals, ghouls, and lycanthropes likely appear with the evil eye in Figure 1, because they all tend not to use sorcery (shifting them high on PC2) and they lack most other witchy qualities (shifting them low on PC1).

In Figure 1, I colored the points according to the ethnographer's name for that practitioner. These colors cluster, showing that terms like "sorcerer" or "witch" in fact capture cross-culturally recurrent beliefs. Sorcerers (blue) are normal humans who use effigies, curses, and other spells to harm their rivals. Descriptions of sorcerers are very similar to descriptions of people generally knowing and using dark magic (purple). Possessors of the evil eye (yellow) harm people with their stares and words, often unintentionally. They do not employ spells, and their powers tend to be inborn rather than actively procured. Witches (pink) are much more variable across societies, but they share up to three sets of traits: (1) They are threatening (e.g., they kill and conspire in secret, nighttime meetings), (2) they are supernaturally powerful (e.g., they fly and transform into animals), and (3) they are abhorrent (e.g., they consume human flesh and desecrate corpses) (see Figure 2). This results of the PCA suggest that witchiness is a dimension rather than a discrete trait - that is, some societies describe practitioners who are more threatening, supernaturally powerful, and abhorrent than the practitioners described in other societies.

\footnotetext{
${ }^{8}$ Several variables, all of which appeared very infrequently in the MHS, had unstable loadings that collapsed when the data from a single region were excluded from the PCA (see Supplementary Materials, section 2.2 and Supplementary Tables 5 and 6). I have not reported these unstable loadings here, but see Supplementary Table 2 for the full factor matrix.
} 

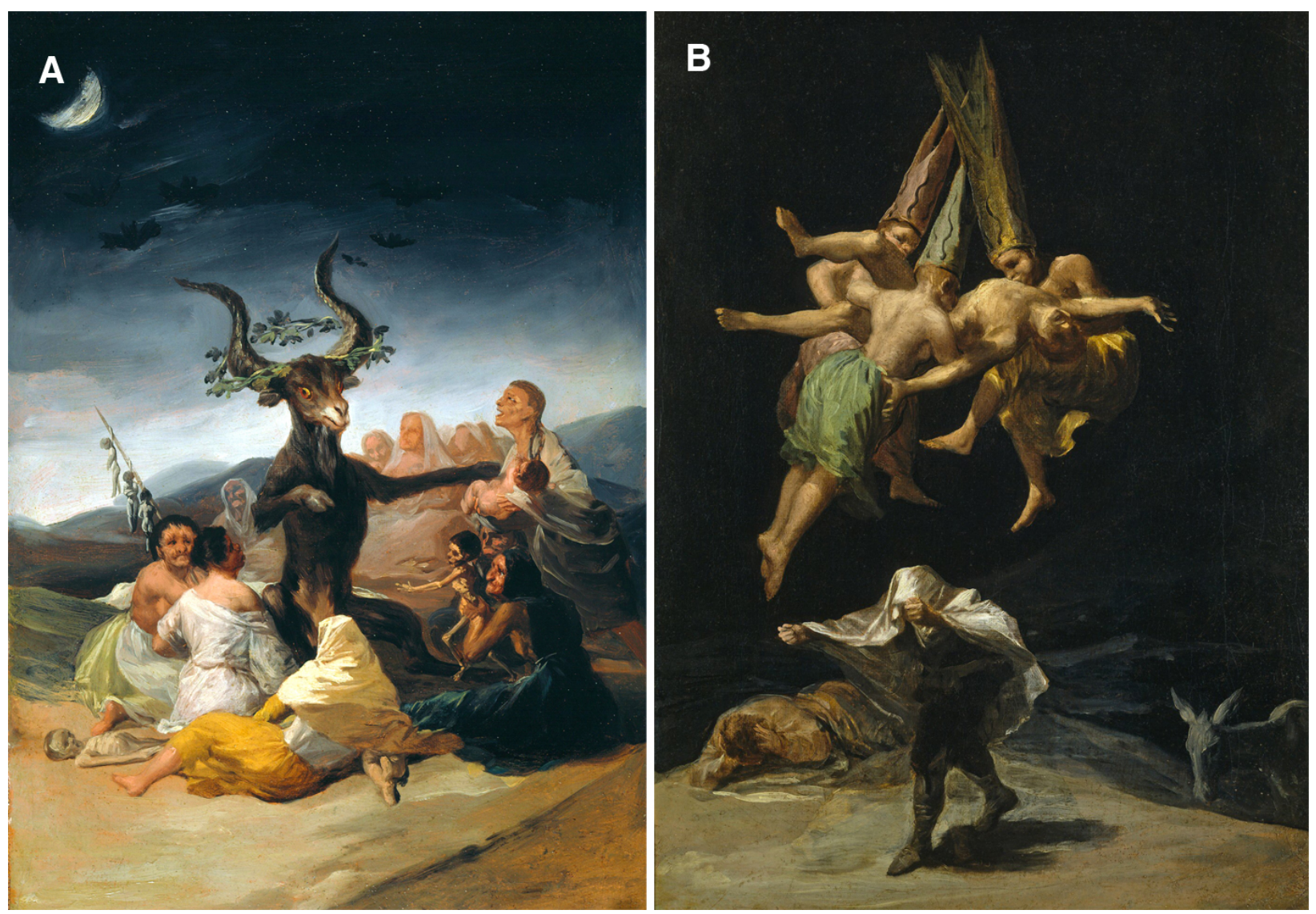

Figure 2. (A) Witches' Sabbath (Goya, 1798; CMuseo Lázaro Galdiano, Madrid) and (B) Witches' Flight (Goya, 1798; (Photographic Archive Museo Nacional del Prado) depict conceptions of witches held by many medieval Europeans. The witches are nude and nocturnal; they fly, kill babies, devour human flesh, associate with nighttime animals, and conspire with evil spirits. Despite their strangeness and particularity, these traits were not restricted to medieval European witches. People around the world - including the Tlingit (Pacific Northwest), the Akan (West Africa), and the Trobriand Islanders (South Pacific) - held similar conceptions of witches.

The analysis helps reconcile a historic debate about the difference between witches and sorcerers. Evans-Pritchard (1937) drew a strict boundary between the two, specifying that malicious practitioners are either normal humans who use magic (sorcerers) or different entities who do not use magic, instead attacking with supernatural powers (witches). He used the dichotomous scheme to describe Azande beliefs in particular, but other anthropologists applied the same typology to different ethnographic contexts (e.g., Reynolds 1963; but see Turner 1964).

Figure 1 reveals that Evans-Pritchard's witch-sorcerer binary does not generalize. Some heinous, supernaturally powerful practitioners (witches) only attack with supernatural stares and thoughts, such as those of the Azande (9) and Akan (1), but many are believed to also employ spells, charms, and other material magic. Some witches, for example, stuffed effigies into the carcasses of dead puppies (Tlingit: De Laguna 1972:730); others recited spells to fly (Trobriand Islanders: Malinowski 1922:241) or used horseshoes and keys to conjure evil spirits (Colonial New England: Karlsen 1987:9). Thus, witches resemble other malicious practitioners, such as 


\section{ON THE ORIGINS AND DESIGN OF WITCHES AND SORCERERS}

sorcerers or possessors of the evil eye, except transformed along a dimension of witchiness, made more threatening, more abhorrent, and more supernaturally powerful.

\section{Existing theories of mystical harm}

The most influential theories of mystical harm ascribe a function to these beliefs, often regarding them as group-level adaptations. Most popular is the theory that these beliefs discourage socially unacceptable behavior. According to this theory, if people suspect that their irate neighbors will attack them with evil spells and powers, then people will refrain from upsetting each other, both to avoid being attacked by mystical harm and to avoid being accused (Whiting 1950; Beattie 1963; Walker, Jr. 1967).

Faulkingham (1971:112) summarized this theory in observations of the Hausa (Niger): "Sorcery beliefs in Tudù provide people with strong motivations to be gregarious and to avoid quarrels. One is hesitant to be silent, alone, or bickering, lest he be accused of being a sorcerer. Further, people are reticent to exacerbate quarrels, for they may become ensorceled." But he also recognized that these beliefs entail major costs: "While sorcery beliefs have these social control functions, I believe that the villagers pay a high psychological price, since hostile emotions are relentlessly proscribed" (Faulkingham 1971:112).

Other researchers have echoed Faulkingham's second point, disputing cooperation theories by noting how sorcery and witchcraft beliefs sow distrust and provoke quarreling (Gershman 2016; see Hutton 2017:35 and works cited therein). Among the Kapauku Papuans, most wars in one region (Mapia) started because of presumed sorcery; in another (Kamu), sorcery accounted "for about thirty per cent of the conflicts" (Pospisil 1958:154). Other examples of contexts in which sorcery and witchcraft accusations bred violence abound (e.g., Gebusi: Knauft 2010; Rajputana: Skaria 1997; Yolngu: Warner 1958; Zulus: Bryant 1929). Suspicions of magical harm can even inspire vitriol among family members, such as when a Klamath woman slayed "her own mother for the fatal bewitchment of her child" (Stern 1965:21). An ethnographer quoted the Santal (South Asia) guru Kolean Haram, who summarized the sociological and psychological stresses of witchcraft beliefs: "The greatest trouble for Santals is witches. Because of them we are enemies of each other. If there were no witches, how happy we might have been" (Archer 1984:482).

Other scholars argue that beliefs in mystical harm explain misfortune. Evans-Pritchard (1937) famously proposed this hypothesis in his report on Azande witchcraft. But the claim that witchcraft beliefs explain misfortune cannot account for many features of those beliefs. Most notably, why should people suspect that group mates engineer misfortune through magic or supernatural powers when they can already blame gods, water demons, and other purported, invisible harmful forces? Addressing this gap, Boyer (2001) pointed out that we are predisposed to think about other people harming us. Humans are social animals, he observed, constantly engaged in reciprocal favors. Thus, he hypothesized, we have evolved psychological mechanisms that often interpret misfortune either as someone cheating us or as punishment for apparently cheating others. As people adopt or develop explanations that conform to these expectations, they produce beliefs in mystically powerful cheaters and cheater-detectors: "People who give others the evil eye are overreacting cheater-detectors and witches are genuine cheaters" (Boyer 2001:200). 


\section{ON THE ORIGINS AND DESIGN OF WITCHES AND SORCERERS}

I borrow elements of the explanation hypothesis, but Boyer's formulation suffers from some of the same flaws as Evans-Pritchard's: Both leave the content of witchcraft beliefs largely unexplained, including why people use spells or charms or why witches transform into animals and mutilate corpses. Boyer's account also confronts a problematic inconsistency: If people with the evil eye are "overreacting cheater-detectors", then why is the evil eye linked so often to envy (Dundes 1992), rather than feelings of being cheated?

Finally, many researchers connect mystical harm beliefs to sociological events, such as the envy, inequality, and redistribution associated with social change (Comaroff and Comaroff 1999; Bohannan 1958), the control of women (Hester 1992; Natrella 2014), and scapegoating (Oster 2004). But these accounts remain atomized and disconnected. They focus on single determinants (such as rising inequality), most of which only apply in some circumstances, while failing to describe many of the features of mystical harm beliefs.

I have left out many other explanations for these beliefs, including ones that invoke repressed sexual impulses (Cohn 1976), distorted perceptions of existing or historic cults (Murray 1921), the inadvertent consumption of ergot fungi (Caporael 1976; Alm 2003), and delusions resulting from psychiatric illness (Field 1970). These accounts suffer from many of the same criticisms as those reviewed above. Not only do they fail to explain the content of mystical harm beliefs, they also leave open the question of how shifting conditions should elicit some beliefs but not others.

\section{Introducing the tripartite theory: Cultural selection}

I propose that mystical harm beliefs develop from the interaction of three cultural selective processes. Cultural selection occurs when people preferentially retain particular practices or beliefs, such as because they appear to more effectively produce a desired outcome (Blackmore 1999; Boyd and Richerson 1985; Campbell 1965; Sperber 1996). For example, the cultural selection of effective killing technology occurs as people adopt and maintain tools that kill animals or enemies. As people modify their tools and keep the effective versions, they iteratively fashion technology well-designed for killing, like sleek spears or bows-and-arrows. Notably, cultural selection occurs whenever people use culturally-transmitted practices for some desired end and they apply regular criteria to evaluate the effectiveness of those practices. Thus, selection can produce sleek killing technology, but it can also produce chairs, cheesecake, Disney movies, and other delights that satisfy desires humans want.

Cultural selective processes are significant for two reasons. First, they produce complex traditions that no single individual could have devised in a single moment (Henrich 2015). But just as importantly (although less frequently appreciated), these processes retain those traditions. A spear, for example, may be used frequently yet remain unchanged for centuries. Although it does not evolve, people selectively retain it for assassinating game and enemies.

Many scholars assume that cultural selective processes are protracted, involving generations and many individuals, but they don't have to be. Yes, selective processes can occur over many generations: Myths demonizing Jews, for example, evolved over decades as people throughout Europe borrowed and modified each other's existing productions (Cohn 1967). But cultural selection can also produce complex beliefs on very short time-scales with many fewer 


\section{ON THE ORIGINS AND DESIGN OF WITCHES AND SORCERERS}

participants, such as if several people concoct, maintain, and revise heinous myths about a feared sub-group in the hours or days following a catastrophe.

I propose that mystical harm beliefs develop from three cultural selective schemes that produce and maintain (1) intuitive techniques of harmful magic, (2) plausible explanations of misfortune, and (3) myths that demonize a subgroup. The three proposed schemes occur under different circumstances and frequently act independently of each other, separately producing superstitions, conspiracy theories, and propaganda. But they also interact and develop each other's products, giving rise to beliefs in sorcerers, lycanthropes, evil eye possessors, and abhorrent witches. In the following sections, I elaborate on each of these selective processes.

\section{Magic}

Figure 1 shows that people in many societies suspect that their misfortunes are caused by others using sorcery. Why do people accept that sorcery works and presume that others practice it? Here, I argue that these convictions develop from a selection for intuitive magic. People adopt superstitions because of a predisposition to note spurious correlations between cheap actions (such as wearing special underwear) and important, unpredictable outcomes (such as winning a football game). As they then select among superstitions, they choose the most compelling ones, driving the development and maintenance of intuitive magic (see Singh 2018 for an expanded version of this argument). As a consequence, people accept the efficacy of magic, including harmful sorcery, and understand that other group mates know it and might practice it.

\subsection{The selective retention of intuitive magic}

\subsubsection{People adopt superstitions (magic) to influence significant outcomes that are important and unpredictable}

Rubbing rocks before giving speeches, wearing special underwear during football matches, blowing on dice before letting them roll - we regularly use superstitions to nudge uncertainty in our favor. Humans adopt magic or superstitions, which I define as interventions that have no causal bearing on their intended outcome, when those outcomes are important (roughly, fitnessrelevant) and occur randomly (Ono 1987; Keinan 2002; Malinowski 1948). Such outcomes include victory in war, the arrival of rain, recovery from illness, and rivals becoming sick, dying, or suffering economic losses. That we adopt superstitions to control these outcomes seems a result of a kind of bet-hedging psychology. When the costs of an intervention are sufficiently small relative to the potential benefits (like wearing special underwear to win a football match), and when the outcome seems to occur sometimes after the intervention, individuals benefit on average from adopting those interventions (McKay and Efferson 2010; Johnson et al. 2013). The predisposition to adopt superstitions to control uncertainty provides the basis for magical practices across human societies (Vyse 2014), including, I propose, magic for harming others.

\subsubsection{People selectively retain magical interventions that seem the most effective}




\section{ON THE ORIGINS AND DESIGN OF WITCHES AND SORCERERS}

Magic should culturally evolve to become more apparently effective. Humans have intuitions predisposing us to regard some magical techniques, such as those with more steps and repetition (Legare and Souza 2012), as more potent than others. As magic-users iteratively innovate and select these more effective-seeming techniques, they produce intuitive magic. People around the world share biases about how causality and efficacy work, so this selective process should produce cross-cultural similarities in magical techniques (e.g., Nemeroff and Rozin 2000; Rozin et al. 1986), discussed below.

\subsection{Ethnographic evidence for intuitive magic}

At its basis, a selection for intuitive magic demands that people actually attempt to harm each other using magical means. It also predicts that magic will be effective-seeming and that common intuitive principles will characterize both harmful magic and other superstitions. Both claims are supported by the ethnographic record.

\subsubsection{People attempt harmful magic}

People are notoriously reticent about discussing harmful magic with ethnographers, let alone admitting to using it (e.g., Ames 1959:264; Nadel 1954:164). Nevertheless, researchers have successfully documented direct and indirect evidence of people using private sorcery. During his time with the Azande, Evans-Pritchard discovered two bundles of bad medicine in one of his huts. One was engineered "to destroy the popularity of the settlement where I lived by killing some people and making the rest afraid to remain there" (Evans-Pritchard 1937:402). The other was planted to kill the anthropologist. Richards (1935) examined the magical horns collected in a Bemba village during a witch-hunting movement in what-is-now Zambia. Although the vast majority were harmless medicine containers, " 11 out 135 horns were admitted by every one to be undeniably bad destructive magic, that is to say, prepared for the injury of others" (Richards 1935:453). Researchers report other examples such as these (e.g., Anglo-Saxon England: Crawford 1963; Wogeo: Hogbin 1938:231; Tlingit: Emmons and De Laguna 1991:410), although people's admissions of using sorcery and even accounts of other people discovering evidence are difficult to interpret because of the possibility of deception.

Less contestable evidence of people using sorcery is the frequency with which specialists sell harmful services and magicians or laypeople performing evil magic to harm out-group enemies. Specialists sold harmful services in 26 of the 58 societies coded in the expanded MHS, while in at least 10 of those societies, practitioners used magic and supernatural powers to attack enemies of rival groups.

\subsubsection{Malicious magic is governed by the same intuitive principles as other kinds of magic}

The strongest evidence that magic, both harmful and otherwise, develops from a selection for effective-seeming practices is that all kinds of magic are governed by the deeply intuitive principles of sympathetic magic.

Sympathetic magic refers to two causal principles - the law of contagion and the law of similarity (or homeopathy) - which guide magic around the world (Frazer 1920). The law of 


\section{ON THE ORIGINS AND DESIGN OF WITCHES AND SORCERERS}

contagion refers to the implicit belief that "physical contact between [a source object] and [a target object] results in the transfer of some effect or quality (essence) from the source to the target" (Nemeroff and Rozin 2000:3). This principle covers contamination or pollution, in which a negative substance qualitatively changes a target object, as well as notions that acting on a part (for example, on a lock of hair) can have an effect on the whole (for example, the person who once owned it). That we wrongly but frequently believe in contagious magic seems in part a misfiring of psychological mechanisms evolved for noting contamination and illness transmission and perhaps overinterpreting the lingering effects of objects on each other (Rozin and Nemeroff 2002; Apicella et al. 2018).

In contrast to contagion, the law of similarity or homeopathy refers to the impression that "things that resemble each other at a superficial level" - like a voodoo doll that resembles a person - "also share deeper properties" (Nemeroff and Rozin 2000:3) - for example, that acting on the doll produces effects on the imitated target. It remains unclear why people so habitually make this association, but as with the law of contagion, it likely reflects misfiring biases in causal reasoning.

Frazer (1920, Ch. III) famously documented examples of both contagious and similaritybased magic around the world. Among his many cases of contagious magic, he noted that people often believe that one can affect a target by magically treating the impressions it leaves, such as footprints. Footprints feature in malicious magic, like when people tamper with a target's prints to induce illness or pain, and in hunting magic, like when pursuers locate the tracks of animals and doctor them to slow the target (see Table 1). Among his many examples of similarity-based magic, Frazer (1920) documented the frequent belief that one can influence a target by creating and manipulating an effigy of it. Table 1 reviews examples of both malicious and non-malicious magic that uses effigies.

Table 1. Malicious magic is governed by the same intuitive principles of sympathetic causality that structure other kinds of magic. *Examples documented by Frazer (1920).

\begin{tabular}{|c|c|c|}
\hline Magical method & $\begin{array}{l}\text { Examples of malicious magic } \\
\text { (societies with references) }\end{array}$ & $\begin{array}{l}\text { Examples of other magic } \\
\text { (societies with references) }\end{array}$ \\
\hline $\begin{array}{l}\text { Treating the footprints of a } \\
\text { target, such as to harm a } \\
\text { person (malicious magic) or } \\
\text { aid in the capture or warding } \\
\text { off of animals (other magic) }\end{array}$ & $\begin{array}{l}{ }^{*} \text { Chero } \\
{ }^{*} \text { Maori } \\
\text { Natinixwe (Wallace and Taylor 1950, } \\
\text { pp. 189-90) } \\
\text { Niimíípu (Walker, Jr. 1967, p. 74) } \\
\text { Siwai (Oliver 1955, p. 87) } \\
\text { Tswana (Schapera 1952, p. 45) }\end{array}$ & $\begin{array}{l}\text { Ainu (Munro 1963, p. 113) } \\
\text { Azande (Lagae 1999, pp. 146-47) } \\
\text { Fox (Jones 1939, pp. 23-24) } \\
\text { *Khoikhoi } \\
\text { *Nlaka'pamux } \\
\text { Persians (Massé and Messner 1954, } \\
\text { p. 282) }\end{array}$ \\
\hline $\begin{array}{l}\text { Manufacturing and treating } \\
\text { an effigy, such as to injure a } \\
\text { target (malicious magic) or } \\
\text { induce birth or drive away } \\
\text { neighbors (other magic) }\end{array}$ & $\begin{array}{l}\text { Ancient Egyptians (Budge 1901, p. } \\
\text { 75) } \\
\text { Colonial New England (Karlsen } \\
\text { 1987, p. 8) } \\
\text { *Kenyah } \\
\text { *Malay } \\
\text { *Ojibwe }\end{array}$ & $\begin{array}{l}\text { *Basotho } \\
\text { Egyptians (Ammār 1954, p. 89) } \\
\text { *Inuit } \\
\text { *Japanese } \\
\text { *Nisenan } \\
\text { Pomo (Aginsky 1939, pp. 212-13) }\end{array}$ \\
\hline
\end{tabular}


Sami (Karsten 1955, pp. 43-44)

\section{Explanations}

The selection of intuitive magic convinces people that malevolent magic is effective and that others practice it. How does this then transform into beliefs about sorcerers and witches who cause harm?

In this section, I propose that, under certain circumstances, people's hypervigilant tendencies lead them to suspect that group mates engineer inexplicable misfortunes. As they iteratively consider how those group mates harmed them, people maintain a selection for plausible explanations of misfortune. When they believe that sorcery is effective, people may suspect and develop beliefs about sorcerers, although they may consider other means of transmitting harm, such as animal transformation, the evil eye, and even governmental conspiracies.

\subsection{Selection for plausible explanations of misfortune}

\subsubsection{People suspect distrusted group members in the wake of impactful, negative outcomes}

Whether we lose a wallet or observe an epidemic sweeping through our community, we commonly attribute impactful, hard-to-explain events, especially negative ones, to the wicked intentions of other humans (Tennen and Affleck 1990). These tendencies seem to have evolved to vigilantly recognize threat (Raihani and Bell 2018). Our social lives are marked by conflict, so we benefit from tracing and anticipating when spiteful others harm us, even if it means making occasional mistaken attributions (see error management: Johnson et al. 2013; McKay and Efferson 2010).

A growing body of literature, most of it in the psychological sciences, shows that a person is most likely to suspect other people for causing some misfortune under four conditions:

(1) The person feels threatened (Abalakina-paap et al. 1999; Mirowsky and Ross 1983; Saalfeld et al. 2018; Mashuri and Zaduqisti 2015);

(2) They are distrustful of others (Abalakina-paap et al. 1999; van Prooijen and Jostmann 2013; Raihani and Bell 2017);

(3) They confront an event that is hard to explain (Rothschild et al. 2012; van Prooijen and Douglas 2017; van Prooijen and Jostmann 2013);

(4) That event is impactful (van Prooijen and Douglas 2017; van Prooijen and van Dijk 2014; McCauley and Jacques 1979).

These conditions are enlightening for two reasons. First, they provide evidence for adaptive hypotheses of paranoid thinking. People benefit from identifying mean-spirited rivals who conspire to harm them, so it's reasonable that our psychology has evolved to seek out these individuals when they are most likely to harm us. Second, identifying these conditions generates predictions for the contexts under which people are most likely to develop beliefs in mystical harm. If some adaptive psychological machinery provides a psychological foundation for sorcery and witchcraft, then the conditions that trigger that psychology should in turn breed suspicions of mystical harm. I discuss these predictions in section 6.2. 


\section{ON THE ORIGINS AND DESIGN OF WITCHES AND SORCERERS}

\subsubsection{People selectively retain plausible explanations for how group mates harmed them}

Humans constantly seek explanations (Frazier, Gelman, and Wellman 2009; Lombrozo 2006). When your money-purse goes momentarily missing in a coffee shop and you suspect the wait staff or your fellow patrons, you automatically consider the various ways by which they might have accomplished their misdeed. You deem some explanations likelier than others - for example, that it was stolen once rather than stolen and returned and then stolen again, or that it was stolen by the grungy crust-punk rather than by the well-to-do suburban family to his left. The process of inferring an explanation by comparing hypotheses against each other and selecting the best among them is known as "inference to the best explanation" (Harman 1965).

People suffer many hard-to-explain misfortunes, such as illness, the death of a loved one, and a burnt-down house. I propose that as they search for explanations for how suspected rivals engineered those harms, they retain the most plausible explanations. A distrustful person whose livestock dies, for example, will search for an explanation for how a rival committed the act. They will consider explanations that they have learned, concoct other stories, and ask knowledgeable group mates. As other people suffer similar, inexplicable injuries, and as people share their conclusions and suspicions with each other, communities spin more and more conceivable tales for how heinous group members abused them from afar. When people believe in the efficacy of malicious magic (following section 5), it provides a sufficient and parsimonious answer, easily accounting for invisible, distant harm.

In societies without strong beliefs in magic, this selective process still occurs, although it converges on different explanations. One explanation is that powerful governments mastermind misfortune. In his analysis on paranoia in US politics, Hofstadter (1964) noted that people often attribute their troubles to distrusted governments or the puppeteers controlling them, such as the Catholics, Free-Masons, and Illuminati. Barkun (2013) showed that these theories evolve.

Milton Cooper, for example, tweaked and synthesized existing theories about the Illuminati, the CIA, the Kennedy assassination, observations of cattle mutilations, and the AIDs epidemic. His super-conspiracy theories comprehensively explained both the momentous and the puzzling, producing an unparalleled appeal. As I am write this, his 1991 book Behold a Pale Horse (Cooper 1991) ranks $2,998^{\text {th }}$ among all books on Amazon.com, besting the highest-selling editions of The Iliad, War and Peace, and Uncle Tom's Cabin.

Beliefs about mystical practitioners should evolve like contemporary conspiracy theories. Over time, they should become more internally consistent and plausible while encompassing a wider set of inscrutable events.

\subsection{Ethnographic evidence for plausible explanations of misfortune}

I have argued that beliefs in mystical harm develop to explain how distrusted group mates attacked a person from afar. At least two basic predictions follow: (1) Beliefs in mystical harm should track distrust and suspicions of harmful intent, and (2) malicious practitioners should be suspected of causing calamitous, negative events, especially ones for which people lack alternative explanations. Meanwhile, that these beliefs develop from a selection for the most plausible explanations clarifies why malicious practitioners often associate with, and transform into, animals. 


\section{ON THE ORIGINS AND DESIGN OF WITCHES AND SORCERERS}

\subsubsection{Accusations of mystical harm track distrust and suspicions of harmful intent}

People who suffer calamity overwhelmingly suspect individuals with a presumed interest in harming them. When several girls fell into possessed fits in Salem Village in 1692, many of the girls' families' political rivals were suspected of attacking the girls and their allies (Boyer and Nissenbaum 1974). Among the Azande, "A witch attacks a man when motivated by hatred, envy, jealousy, and greed... Therefore a Zande in misfortune at once considers who is likely to hate him" (Evans-Pritchard 1937:100). For the Trobriand Islanders, "the passions of hatred, envy, and jealousy" are expressed "in the all powerful sorcery of the bwaga' $u$ [sorcerer] and mulukwausi [witch]" (Malinowski 1922:395). Many ethnographers studying other societies have made similar comments (e.g., Tlingit: De Laguna 1972:730; Tikopia: Firth 1954:114; Ona: Gusinde 1971:1102; Tukano: Reichel-Dolmatoff 1971:156-157; Pawnee: Weltfish 1965:337).

People regard envy in particular as a potent, malicious emotion. They not only suspect that envious individuals want to harm them, but in societies everywhere, people believe that the emotion itself transmits mystical harm, such as through covetous stares (the evil eye) or jealous compliments (the blasting word) (Dundes 1992). Beliefs in the harmful effects of envy likely exist because envy drives malice. Individuals who experience envy are more likely to injure betterpositioned targets (Smith and Kim 2007; Miceli and Castelfranchi 2007) and even derive pleasure when envied persons suffer (van de Ven et al. 2015; Smith et al. 1996). Thus, a person who expresses envy betrays a desire to harm, making them a key suspect after things go wrong.

The theory proposed here also predicts that beliefs about witches, sorcerers, and evil eye possessors should prosper in communities with lower levels of trust compared to those with higher levels. This explains why mystical harm beliefs increase with conditions that exacerbate distrust, such as growing inequality and the resulting rise in envy (e.g., Lederman 1981). ${ }^{9}$

\subsubsection{Mystical harm explains impactful and unexplainable misfortunes}

I argued that paranoid tendencies intensify when the impact of a misfortune is high and it is unexplainable. If beliefs in mystical harm develop from these tendencies, people should fault malicious practitioners for high-impact and inexplicable injuries.

People overwhelmingly accuse malicious practitioners of causing impactful hardship. Of the 83 practitioners or practices in the MHS, at least 78\% were said to cause illness, $77 \%$ death, $30 \%$ economic trouble, and $16 \%$ catastrophes (such as hailstorms or epidemics). In total, $94 \%$ were reported as producing at least one of those outcomes.

Ethnographic descriptions often focus on the inexplicability of these hardships (e.g., Nsenga: Reynolds 1963:19; Kerala Brahmins: Parpola 2000:221). The Navajo attributed illnesses to witchcraft when they were "mysterious from the Navaho point of view" or "persistent,

\footnotetext{
${ }^{9}$ Analyzing Pew survey data in nineteen sub-Saharan African, Gershman (2016) reported a robust, negative correlation between the prevalence of mystical harm beliefs and several measures of trust. He acknowledged that the evidence was correlational yet preferred the interpretation that mystical harm beliefs erode trust. This is reasonable - people who understand illness and death to be the handiwork of evil group members should grow more distrustful of them - but the proposed theory also predicts the opposite direction of causality. As I discussed, people who distrust others should suspect them of causing unexplainable misfortunes, and sorcery provides a parsimonious explanation.
} 


\section{ON THE ORIGINS AND DESIGN OF WITCHES AND SORCERERS}

stubbornly refusing to yield to usual Navaho treatment" (Kluckhohn 1944:54). Other strange circumstances, such as the appearance of unexplained tracks, were taken as further evidence. When the Tiwi experienced a decrease in mortality from fighting, raids, and neglected wounds, they attributed the resulting increase in natural deaths to a rise in poison sorcery (Pilling 1958:123).

People attribute random calamities aside from death, disaster, illness, and material loss to mystical malice. Ten of the 83 practitioners in the MHS were said to produce sterility; 12 influenced love and attraction. Witches in colonial New England were rumored to cause clumsiness, falling, fires, forgetfulness, barrenness, deformed children, spoiled beer, storms, sleep paralysis, and unusual behavior in animals (such as a cow wandering off or a sow knocking its head against a fence) (Karlsen 1987). Table 2 includes every example of harm or misfortune recorded in the MHS that does not qualify as death, injury, love, sterility, catastrophe, or economic trouble. Nearly early all are inexplicable and bothersome.

Table 2. Every example of harm or misfortune recorded in the MHS that does not relate to death, injury, sickness, love, sterility, catastrophe, or economic trouble. Citations appear in the MHS dataset.

Society (with practitioner* and MHS practitioner ID)

Akan, obayifo/witch [1]

Amhara, buda/evil eye [3]

Aymara, laiqa/sorcerer [8]

Azande, aboro mangu/witch [9]

Azande, aira kele ngrwa/sorcerer [10]

Azande, irakörinde/possessor of teeth [11]

Azande, women's sexual magic [12]

Chukchee, sorcery [22]

Chuuk, souboud/sorcerer [23]

Dogon, yadugonu/witch [27]

Highland Scot, buidseachd/witchcraft [40]

Hopi, bowaka/witch [42]
Harm of misfortune

Accidents (including lorry accidents); bad behavior of wife; becoming a drunkard; burnt-down house; cracks in buildings; ill luck; poor performance on school exams; pregnant men

Croaking or worsening of singer's voice

Accidents; failure in fishing

Burnt-down hut; coldness of prince towards subject; failed magic; ruined performance of witch-doctor; sulkiness or unresponsiveness of wife

Outcome of divination (poison oracle)

Broken items, including stools, pots, and bowls

Bad luck

Losing strength while wrestling; slowing down in a foot- or reindeer-race

Disturbed growth; falling or tripping during competition (basketball)

Temporary muteness

Stuck or overturned truck

Malicious gossip; misbehavior of children 


\section{ON THE ORIGINS AND DESIGN OF WITCHES AND SORCERERS}

Iroquois, witch [47]

Lau Fijians, raw eyes [61]

Lozi, muloi/witch [64]

Ojibwa, windigo/cannibal spirit [71]

Pawnee, witch [74]

Santal, sorcery [77]

Saramaka, sorcery [78]

Tarahumara, sukurúame/sorcerer [89]

Tiv, mbatsav/witch [91]

Tlingit, land otter sorcery [93]
Confusion in sports competitions

Skin discoloration (i.e., becoming tan)

Inability to perform acrobatics; inability to score during football

Overturned canoes

Stopped rain

Deception

Boat accidents

Outcomes of competitions (e.g., races); twins

Appearance of baldspots; bad dreams; burnt clothes; "whatever goes wrong if there is no more convenient explanation"

Disappearance

*The indigenous term for the practitioner or practice with the ethnographer's term or translation

\subsubsection{Animals associated with mystical harm explain impactful misfortune and invisible harm}

Those animals associated with malevolent supernatural practitioners provide further evidence that these beliefs serve as compelling explanations of misfortune. Table 3 displays all of the animals associated with harmful practitioners recorded in the MHS, separated into those animals believed to be transformed practitioners and those animals that act as their servants, steeds, or helpers.

Table 3. Every example in the MHS of practitioners either transforming into animals (including the practitioner's soul entering or becoming an animal) or working with animals (including spirit familiars taking animal form). Citations appear in the MHS dataset.

Animals into which practitioners transform

Society

(with practitioner* and MHS practitioner ID)

Akan, obayifo/witch [1]

Amhara, buda/evil eye [3]

Azande, aboro mangu/witch [9]

Bahia Brazilians, lobishomem/werewolf [15]

Dogon, lycanthrope [28]
Animal

Antelopes, bulls, bushpigs, centipedes, cows, crop worms, crocodiles, dogs, hyenas, leopards, lions, lizards, owls, rats, red deer, snakes (including poisonous ones), squirrels, tsetse fly

Hyenas

Bats

Wolves

Eagles, panthers 


\section{ON THE ORIGINS AND DESIGN OF WITCHES AND SORCERERS}

Eastern Toraja, topokantoe/sorcerer [29]

Eastern Toraja, taoe mepongko/werewolf [30]

Garo, lycanthropy [36]

Hopi, bowaka/witch [42]

Iroquois, witch [47]

Kapauku, meenoo/cannibal [53]

Lozi, muloi/witch [64]

Mataco, ayieu/sorcerer [68]

Santal, tonhi/witch [76]

Serbs, vjestice/witch [79]

Tiv, mbatsav/witch [91]

Tlingit, nukwsati/witch [92]

Trobriand Islanders, yoyova/flying witches [94]

Wolof, doma/witch [101]

\section{Snakes}

Buffalo, cats, deer, dogs, pigs, white ants

Any beast or reptile, including crocodiles, snakes, and tigers

Animals, including coyotes, foxes, lizards, and wolves

Any animal, including dogs, pigs, turkeys, and owls

Dogs, hawks

Hyenas, lions

Horses, jaguars, venomous reptiles (including rattlesnakes)

Bears

Insects, reptiles, sparrows

Chicken leopards (?), crocodiles, foxes, leopards, lions, monkeys, owls, witch cats (?), other birds (akiki, kpire)

Cranes, geese, owls, porpoises, sea lions

Fireflies, flying foxes, nightbirds

Ants, cats, donkeys, hyenas, monkeys, owls, snakes, vultures

Animals associated with practitioners

(e.g., familiars, mounts)

Society

(with practitioner* and MHS practitioner ID)

Akan, obayifo/witch [1]

Amhara, buda/evil eye [3]

Aymara, laiqa/sorcerer [8]

Azande, aboro mangu/witch [9]

Bahia Brazilians, lobishomem/werewolf [15]

Bemba, muloshi/witch [17]

Blackfoot, medicine [18]
Animal

Antelopes, bats, chameleons, cocks, crabs, dogs, eagles, electric fish, goats, horses, house flies, leopards, lions, lizards, lice, owls, rats, smart hawks (?), snakes (including black mambas, black snakes, green mambas, puff adders, pythons, spitting cobras, thrush striped snakes), soldier ants, tsetse flies, wasps, weaver birds, wolves

Hyenas

Nighthawks, owls

Nocturnal birds and animals, including bats, jackals, and owls

Dogs

Magical birds, owl-like birds

Spiders 


\section{ON THE ORIGINS AND DESIGN OF WITCHES AND SORCERERS}

\author{
Chukchee, sorcery [22] \\ Eastern Toraja, taoe mepongko/werewolf [30] \\ Eastern Toraja, taoe meboetoe/werewolf [31] \\ Garo, lycanthropy [36]
}

Hopi, bowaka/witch [42]

Lozi, muloi/witch [64]

Ojibwa, witchcraft [72]

Pawnee, witch [74]

Santal, tonbi/witch [76]

Serbs, vjestice/witch [79]

Tarahumara, sukurúame/sorcerer [89]

Tiv, mbatsav/witch [91]

Tzeltal, witch [100]

\author{
Dogs, reindeer \\ Black cats, snakes \\ Black cats
}

Animals that live in the forest, including elephants, crocodiles, snakes and other reptiles, and tigers

Lizards

Jackals, lizards, nightjars, owls, rats, water-snakes

Snakes, wolverines

Owls

Dogs, tigers

Birds, insects, small reptiles, snakes

Invisible birds

Cats, nightjars, owls, snakes

Snakes

*The indigenous term for the practitioner or practice with the ethnographer's term or translation

A cursory glance reveals that many of the animals fall into one of two categories. First are those creatures responsible for calamities, such as man-killers and crop-destroyers. Snakes, bears, tigers, wolves, and crocodiles all attack humans, leaving wounded individuals searching for explanations. Hypervigilant people should immediately suspect their enemies, and ethnographic descriptions show that this frequently occurs. To the Akan, snakes bring "sudden and most unpleasant death", so "anyone who has a narrow escape from a snake comes to ask who sent it and why" (Field 1970:130). Archer (1984:486) recorded an incident among the Santal of South Asia when a man was mauled by two bears. He soon consulted a witch finder to learn who was behind the attack.

Another class of ruinous misfortune is the destruction of crops. The Akan accused witches of becoming squirrels, rats, crop worms, antelopes, bush pigs, cows, bulls, dogs, and red deer - but all of those suspicions followed incidents when those animals consumed or destroyed a person's harvest (Debrunner 1961).

The second major category includes those animals whose alliance or transformation explains how dark practitioners commit their wickedness unseen, such as owls, nightjars, flying foxes, and fireflies. In all of these instances, people seem confident that a group mate harmed them and, noticing these animals flitting about, find their appearance the missing explanatory piece for how a distrusted rival harmed them.

Several animals do not fall into the above categories, but their associations with malicious practitioners still seem to parsimoniously explain puzzling events. The Tlingit believed that witches could become porpoises and sea lions, but these suspicions occurred when those animals behaved enigmatically, lacking "the normal fear of human beings displayed by ordinary wild animals" (de Laguna 1972:731). Thus, an ailing sea lion that remained near people's houses and porpoises that swam too close to shore were suspected of being metamorphosed witches. 


\section{ON THE ORIGINS AND DESIGN OF WITCHES AND SORCERERS}

Hyenas were associated with malicious magicians among the Wolof, Amhara, and Lozi, as well as many cultures not included in the MHS, such as the Kaguru of Tanzania (Beidelman 1975) and Persians in medieval India (Ivanow 1926). This association seems the result of demonizing narratives feeding back on plausible explanations. If people believe that certain individuals have superpowers and feast on human flesh (as shown in Figure 1 and discussed in the next section), they should start to suspect transformation when they witness nocturnal hyenas digging up corpses.

\section{Evil}

The above two processes fail to explain the extreme heinousness of witches, such as their cannibalism and graveyard conspiracies. Here, I propose that these features develop from a selection for demonizing narratives - specifically, from a selection for those traits that justify the mistreatment of accused practitioners and even spur other group mates to remove them.

\subsection{Selection for demonizing narratives}

\subsubsection{People promote demonizing narratives when they want to justify mistreatment of a group}

The cannibalism, conspiratorial meetings, and existential threat posed by witches are peculiar commonalities, but they are not unique. Sociologists studying moral panics and elimination campaigns in Western contexts have documented similar "folk devils", with target groups ranging from youth sub-cultures (Cohen 1972) to Jews (Cohn 1967; Cohn 1966). Their analyses, together with insights from psychological research, reveal why these narratives recur with such consistency around the world.

Folk demonization usually occurs because one group - hereafter, the Campaigners wants to justify the mistreatment of another - hereafter, the Targets (Goode and Ben-Yehuda 2009). Targets can be social groups, such as Jews or heretics, but they can also be those people who do some behavior, like people who use LSD (Goode 2008).

Campaigners demonize Targets for several, non-exclusive reasons, including (a) competition, such as when removing Targets opens up resources, (b) existential fear, such as when Targets are believed to threaten Campaigners, and (c) moral campaigns, such as when Campaigners want to curb some behavior. The foundations of these motivations can be legitimate, like if removing victims frees up benefits that the Campaigners can enjoy (e.g., Philip IV's motivation to arrest the Knights Templar: Barber 2006), or mistaken, such as when Campaigners wrongly understand Targets to be threatening (e.g., panics about satanic groups: Victor 1989).

To mistreat Targets, Campaigners must often gain the approval of other group mates hereafter, the Condoners. They can secure this approval by promoting sensational myths that justify abusing the Targets. People might craft these myths deliberately, as in many propaganda campaigns (e.g., Desforges 1999), but they can also do so unconsciously. People reflexively attend to and exaggerate evidence that supports their goals and their claims (Nickerson 1998; Kunda 1990), a tendency arguably designed to sway others (Mercier and Sperber 2011). 


\section{ON THE ORIGINS AND DESIGN OF WITCHES AND SORCERERS}

As Campaigners refine portrayals of Targets that justify and urge violence, they selectively retain demonizing narratives. The iterative crafting of heinous myths about Jews illustrates this process. For example, Cohn (1967) tracked the history of The Rabbi's Speech, a fabricated speech by a chief rabbi describing the Jews' plot to control finance and undermine Christianity. The speech started as a fictional chapter in an 1868 novel recounting a conspiratorial meeting between representatives of the twelve tribes of Israel and the Devil. In the years afterwards, the chapter was borrowed, modified, distributed in pamphlets, and reprinted as purported fact. In an 1881 version from France, the many speeches had been consolidated into a single address, the satanic element was absent, and a note was included explaining that the document came from a forthcoming book by an English diplomat, vouching for its authenticity.

\subsubsection{Demonizing narratives develop and are maintained during stressful uncertainty}

For demonizing narratives to flourish, Condoners need to believe them. But this is often not the case because people are armed with cognitive adaptations that recognize and protect against deception (Sperber et al. 2010). In fact, ethnographers occasionally report people's skepticism about the existence or portrayals of evil magicians (e.g., Tswana: Schapera 1952:44).

Condoners should be gullible or credulous in at least two conditions. First, they should accept information when it comes from influential or trusted sources, such as religious authorities or the media. Second, and more relevantly, people should become receptive when they need valuable information, especially during times of unexplainable stress. Research on social learning and gossip show that uncertainty, especially about important events, motivates individuals to pursue social information (Boyd and Richerson 1988; Laland 2004; Morgan et al. 2012; Rosnow 1991).

In conclusion, times of unexplainable disaster breed paranoid suspicion while leaving injured parties intensely credulous. This combination of mistrust and gullibility allows fearful or exploitative campaigners to invent abominable witches.

\subsection{Ethnographic evidence for demonization}

\subsubsection{Witches are well-designed to induce punitive outrage}

In section 2, I showed that witches exhibit many common features, two of the most striking being (1) their threatening nature and (2) their moral abhorrence, especially their cannibalism and defilement of human bodies. These behaviors ignite severe punitive ire, encouraging violence towards those actors.

Depicting a group as an existential threat - organized and secretive yet powerful and conspiratorial - is effective, because, in short, people want to remove threats. A vast literature shows that people are more willing to invest in collective action when they feel existentially threatened (e.g., Johnson and Frickel 2011; Berry 2015; Maher 2010). Meanwhile, researchers note that people use past harms committed by a group to justify violence and mistreatment towards it (Sullivan et al. 2012) and people forgive aggressors when reminded of these wrongs (Wohl and Branscombe 2009). If narratives develop to maximally support and provoke violence 


\section{ON THE ORIGINS AND DESIGN OF WITCHES AND SORCERERS}

towards demonized Targets, Targets should be portrayed as representing as large a threat as is believable.

Aside from conspiratorially plotting destruction, witches engage in atrocious behaviors, most frequently cannibalism and corpse desecration, but also acts such as necrophilia (e.g., Navajo: Kluckhohn 1944) and incest (e.g., Apache: Basso 1969; Kaguru: Beidelman 1963). What accounts for their pervasiveness? As readers can attest, these acts trigger an intense, visceral moral outrage (Haidt, Björklund, and Murphy 2000). For the !Kung, "the two worst sins, the unthinkable, unspeakable sins, are cannibalism and incest" (Marshall 1962:229), while among the Comanche, "the very idea that one of them might under stress eat another person was vigorously repulsed" (Wallace and Hoebel 1952:70). In fact, the repugnance at cannibalism is so intense that some societies even claim to forbid the consumption of animals that resemble humans, exemplified in taboos on the Amazon river dolphin and nutria (a large semiaquatic rodent) among the Warao (Wilbert 1972:69).

One possible reason for our revulsion at acts like cannibalism and necrophilia is that they indicate that an actor is dangerous and not to be trusted. People may have evolved psychological mechanisms to select social partners who are predictable and safe. Any individual who even considers an atrocious behavior, like consuming flesh, having sex with dead bodies, or mutilating corpses, reveals an underlying preference that makes them perilous social partners (Tetlock 2003; Hoffman, Yoeli, and Nowak 2015). Our revulsion at these acts may be enhanced by feelings of disgust, which have been shown to heighten moral judgment (Schnall et al. 2008).

Regardless of why we abhor cannibalism and other obscenities, the broader point is that those acts invite severe punitive outrage, making them potent for justifying and urging elimination. Should some other set of behaviors provoke greater outrage, the proposed theory predicts that witches will do those instead (assuming that people will believe the accusations).

\subsubsection{Witches resemble the demonized targets of other moral panics and eradication campaigns}

The traits of witches are sensational and atrocious, but they are not unique. Other panics and campaigns of mistreatment - such as attacks on heretics and dissidents, moral panics during times of stress, and conspiracy scares - similarly transform targets into witch-like demons. Table 4 lists some examples. Note how frequently these groups supposedly pose existential threats and violate sacred values.

Table 4. The targets of moral panics and elimination campaigns resemble witches, especially by posing existential threats and violating sacred values.

\begin{tabular}{ll}
\hline \hline Selected groups & Traits ascribed (with references) \\
\hline Christians, & Worship a donkey-god or genitals of priest; engage in secretive \\
100s, Roman Empire & $\begin{array}{l}\text { meetings, infanticide, child-cannibalism, and nighttime, incestuous } \\
\text { orgies; "threaten the whole world and the universe and its stars with } \\
\text { destruction by fire" (Felix and Rendall 1972, p. 337-41) }\end{array}$
\end{tabular}




\section{ON THE ORIGINS AND DESIGN OF WITCHES AND SORCERERS}

Knights Templar, early 1300s, France

Mau Mau rebels, 1950s, Kenya

Communists, 1965, Indonesia

Tutsis, early 1990s, Rwanda Christian sect), 1466, Rome

Catholics, mid-1800s, United States
Deny Christ; spit, trample, and urinate on the cross; engage in homosexual practices, including disrobing newcomers and kissing them; collect in secret meetings at night; are bound by oaths enforced by death; swear to advance the Order at all costs, lawful or not (Barber 2006, p. 202-203)

Fraticelli "de opinione" (radical

Enjoy nighttime orgies in crypts; sacrifice a small boy, make powder from his body, and consume it communally in wine during mass (Cohn 1976, p. 46)

"The anti-Catholics invented an immense lore about libertine priests, the confessional as an opportunity for seduction, licentious convents and monasteries... Infants born of convent liaisons were baptized and then killed" (Hofstadter 1964, p. 80-81).

Mutilate victims' corpses; take secretive oaths at night that involve obscenities like public masturbation and drinking menstrual blood (Lonsdale 1990, p. 398-400)

Murder, torture, and castrate generals; woman's Communist group dances naked at night; plot nation-wide purge of anti-Communists (Henry 2014; Wieringa 2011)

Send women to seduce Hutu and infiltrate positions of power; plot a war to reestablish control, massacre Hutu, and establish Nilotic empire across Africa; admire Nazis and engage in cannibalism; elders kill and pillage and rape girls and women (Desforges 1999, p. 72-83)

\section{Discussion}

\subsection{The origins of sorcerers, lycanthropes, the evil eye, and witches}

Table 5 displays the three cultural selective processes hypothesized to be responsible for shaping beliefs in practitioners of mystical harm. Figure 3 shows how those processes interact to produce some of the malicious practitioners identified in Figure 1 (sorcerers, the evil eye, lycanthropes, and witches).

Table 5. The three cultural selective schemes responsible for beliefs in practitioners of mystical harm.

\begin{tabular}{ccc} 
CULTURAL SELECTIVE & CONTEXTS & FEATURES OF BELIEFS IN \\
SCHEME & When should we expect it to & MYSTICAL HARM \\
What is being selectively & occur? & Which features of mystical harm \\
retained? & & beliefs does this process \\
& & produce? \\
\hline
\end{tabular}




\section{ON THE ORIGINS AND DESIGN OF WITCHES AND SORCERERS}

Intuitive magic (section 5):

Effective-seeming interventions

for harming or killing others

Plausible explanations (section 6): Explanations for impactful misfortune
When people want to harm rivals

Following unexplainable, harmful misfortune, especially when people are distrustful or persecuted

When influential individuals aim to remove a sub-group; during stressful uncertainty
That harm can be transmitted through sympathetic means (contagion, similarity); that harmful magic is effective and that others do it

That impactful and unexplainable harm is caused by magic and supernatural powers; that malicious practitioners are envious or offended; that they associate with animals, especially man-killers and nighttime or tiny animals

That malicious practitioners are threatening (e.g., conspire, kill); that they violate sacred values (e.g., eat corpses)

group

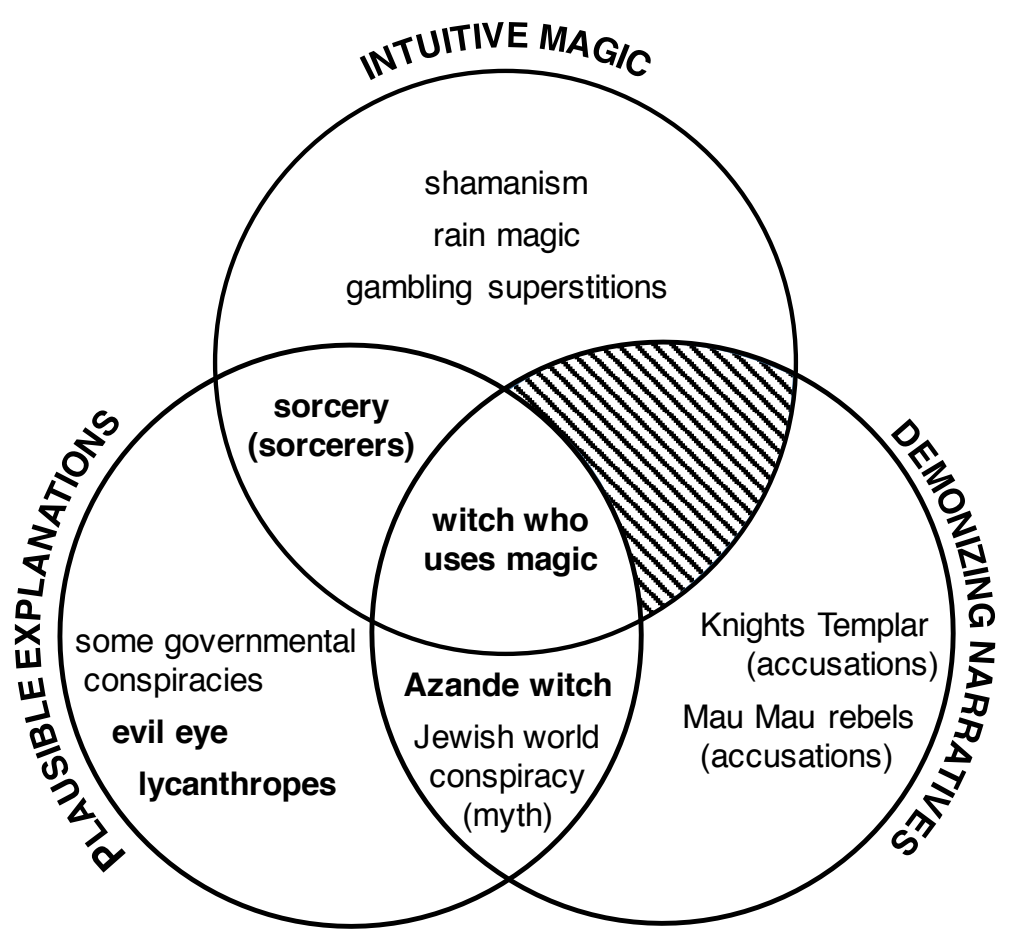

Figure 3. The three selective schemes responsible for beliefs in practitioners of mystical harm. Practitioners of mystical harm are bolded; examples of other practices and beliefs are unbolded. The intersection of demonizing narratives and intuitive magic is filled because no beliefs should exist there - any demonizing narrative in which the target uses magic should also blame the target for terrible events, shifting them to the center. 


\section{ON THE ORIGINS AND DESIGN OF WITCHES AND SORCERERS}

According to the theory outlined here, sorcerers are the result of both a selection for intuitive magic and a selection for plausible explanations. The selection for intuitive magic produces compelling techniques for controlling uncertain outcomes, including rain magic, gambling superstitions, and magic aimed at harming others, or sorcery. Once people accept that this magic is effective and that other people practice it, it becomes a plausible explanation for misfortune. A person who feels threatened and who confronts unexplainable tragedy will easily suspect that a rival has ensorcelled them. As people regularly consider how others harm them, they build plausible portrayals of sorcerers.

Beliefs about werewolves, werebears, weresnakes, and other lycanthropes also develop from a selection for plausible explanations. Baffled as to why an animal attacked them, a person suspects a rival of becoming or possessing an animal and stalking them at night. This explanation becomes more conceivable as the lycanthrope explains other strange events and as conceptions of the lycanthrope become more plausible. Many societies ascribe transformative powers to other malicious practitioners (see Table 3), showing that people also suspect existing practitioners after attacks by wild animals.

Beliefs in the malignant power of stares and words likewise develop to explain misfortune. As reviewed earlier, people around the world connect jealousy and envy to a desire to induce harm. Thus, people who stare with envy or express a compliment are suspected of harboring malice and an intention to harm. A person who suffers a misfortune remembers these stares and suspects those people of somehow injuring them. In regularly inferring how envious individuals attacked them, people craft a compelling notion of the evil eye.

Why suspect the evil eye rather than sorcery? There are at least two possibilities. First, an accused individual may ardently vow not to know sorcery or to have attacked the target (see these claims among the Azande, both described in text: Evans-Pritchard 1937:119-125; and shown in film: Singer 1981, minute 21). Alternatively, given beliefs that effective sorcery requires powers that develop with age, special knowledge, or certain experiences, it may seem unreasonable that a young or unexperienced group mate effectively ensorcelled the target. In these instances, the idea that the stare itself harmed the target may provide a more plausible mechanism.

The famous odious, powerful witch, I propose, arises when blamed malicious practitioners become demonized. People who fear an invisible threat or who have an interest in mistreating competitors benefit from demonizing the target, transforming them into a heinous, threatening menace. Thus, witches represent a confluence of two and sometimes all three cultural selective processes.

In Figure 1, I showed that beliefs about malicious practitioners exist along two dimensions. The tripartite theory accounts for this structure. All of the practitioners displayed are plausible explanations of how group mates inflict harm. One dimension (SORCERY-EVIL EYE) distinguishes those explanations of misfortune that include magic (sorcerers) from those that do not (evil eye, lycanthrope). The other dimension shows the extent to which different practitioners have been demonized. In short, all beliefs about harmful practitioners are explanations; sometimes they use magic, sometimes they're made evil.

\subsection{Ten predictions}




\section{ON THE ORIGINS AND DESIGN OF WITCHES AND SORCERERS}

The proposed theory generates many predictions for how shifting conditions should drive changes in beliefs about malicious practitioners. I referred to several of these throughout the paper. Here are ten (the section of the paper is noted when a prediction is discussed in the paper):

1. People are more likely to believe in sorcerers as sorcery techniques become more effective-seeming.

2. People are more likely to ascribe injury to mystical harm when they are distrustful of others, persecuted, or otherwise convinced of harmful intent. (sect. 6.2.1)

3. The emotions attributed to malicious practitioners will be those that most intensely and frequently motivate aggression. (sect. 6.2.1)

4. People are more likely to attribute injury to mystical harm when they lack alternative explanations. (sect. 6.2.2)

5. The greater the impact of the misfortune, the more likely people are to attribute it to mystical harm. (sect. 6.2.2)

6. Practitioners of mystical harm are more likely to become demonized during times of stressful uncertainty.

7. The traits ascribed to malicious practitioners will become more heinous or sensational as Condoners become more trustful or reliant on information from Campaigners.

8. Malicious practitioners will become less demonized when there is less disagreement or resistance about their removal.

9. The traits that constitute demonization will be those that elicit the most punitive outrage, controlling for believability. (sect. 7.2.1)

10. Malicious practitioners whose actions can more easily explain catastrophe, such as those who employ killing magic compared to love magic, will be easier to demonize.

\subsection{The cultural evolution of harmful beliefs}

Social scientists, and especially those who study the origins of religion and belief, debate over whether cultural traditions evolve to provide group-level benefits (Baumard and Boyer 2013; Norenzayan et al. 2016). Reviving the analogy of society as an organism, some scholars maintain that cultural traits develop to ensure the survival and reproduction of the group (Wilson 2002). These writers argue that traditions that undermine societal success should normally be culled away, while traditions that enhance group-level success should spread (Boyd and Richerson 2010).

In this paper, I have examined cultural traits with clear social costs: mystical harm beliefs. As sources of paranoia, distrust, and bloodshed, these beliefs divide societies, breeding contempt even among close family members. But I have explained them without invoking group-level benefits. Focusing on people's (usually automatic) decisions to adopt cultural traditions, I have shown that beliefs in witches and sorcerers are maximally appealing, providing the most plausible explanations and justifying hostile aims. Corrosive customs recur as long as they are useful and cognitively appealing.

\section{Acknowledgments}




\section{ON THE ORIGINS AND DESIGN OF WITCHES AND SORCERERS}

I thank Mia Charifson for research assistance and Steve Worthington at the Harvard Institute for Quantitative Social Science for statistical help. Nicolas Baumard, Ronald Hutton, Graham Jones, Ted Slingerland, Dylan Tweed, Max Winkler, Richard Wrangham, two anonymous reviewers, and members of the Culture, Cognition, and Coevolution Lab at Harvard University shared comments on earlier drafts of this paper. Luke Glowacki provided detailed feedback on several versions of this manuscript; this paper and the ideas presented in it are much clearer as a result of his incisive suggestions. This research was funded by a graduate research fellowship from the National Science Foundation. 


\section{ON THE ORIGINS AND DESIGN OF WITCHES AND SORCERERS}

\section{References}

Abalakina-paap, Marina, Walter G Stephan, Traci Craig, and W Larry Gregory. 1999. "Beliefs in Conspiracies." Political Psychology 20 (3): 637-47.

Aginsky, B. W. 1939. "Population Control in the Shanel (Pomo) Tribe." American Sociological Review 4 (2): 209-16.

Alm, Torbjørn. 2003. "The Witch Trials of Finnmark, Northern Norway, during the 17th Century: Evidence for Ergotism as a Contributing Factor." Economic Botany 57 (3): 403-16. doi:10.1663/0013-0001(2003)057[0403:TWTOFN]2.0.CO;2.

Ames, David. 1959. "Belief in 'witches' among the Rural Wolof of the Gambia." Africa 29 (3): 263-73.

Ammār, Hāmid. 1954. Growing up in an Egyptian Village: Silwa, Province Of Aswan. London: Routledge and Kegan Paul Ltd.

Apicella, Coren L., Paul Rozin, Justin T. A. Busch, Rachel E. Watson-Jones, and Cristine H. Legare. 2018. "Evidence from Hunter-Gatherer and Subsistence Agricultural Populations for the Universality of Contagion Sensitivity." Evolution and Human Behavior. papers2://publication/uuid/0545B852-08F3-4979-848D-FFD24E70B4D1.

Archer, William George. 1974. The Hill of Flutes: Life, Love, and Poetry in Tribal India : A Portrait of the Santals. Pittsburgh: University of Pittsburgh Press.

- 1984. Tribal Law And Justice: A Report on the Santal. New Delhi: Concept.

Barber, Malcolm. 2006. The Trial of the Templars. 2nd ed. Cambridge, UK: Cambridge University Press.

Barkun, Michael. 2013. A Culture of Conspiracy: Apocalyptic Visions in Contemporary America. 2nd Editio. Berkeley and Los Angeles: University of California Press.

Basso, Keith H. 1969. Western Apache Witchcraft. Tuscon: The University of Arizona Press.

Baumard, Nicolas, and Pascal Boyer. 2013. "Explaining Moral Religions." Trends in Cognitive Sciences 17 (6). Elsevier Ltd: 272-80. doi:10.1016/j.tics.2013.04.003.

Beattie, John. 1963. "Sorcery in Bunyoro." In Witchcraft and Sorcery in East Africa, edited by John Middleton and E. H. Winter, 27-55. London: Routledge \& Paul.

Beidelman, T. O. 1963. "Witchcraft in Ukaguru." In Witchcraft and Sorcery in East Africa, edited by John Middleton and E. H. Winter, 57-98. London: Routledge \& Paul.

- 1975. "Ambiguous Animals: Two Theriomorphic Metaphors in Kaguru Folklore." Africa 45 (2): 183-200.

Berry, Marie. 2015. "From Violence to Mobilization: Women, War, and Threat in Rwanda." Mobilization: An International Quarterly 20 (2): 135-56.

Blackmore, Susan. 1999. The Meme Machine. Oxford, UK: Oxford University Press.

Bohannan, Paul. 1958. "Extra-Processual Events in Tiv Political Institutions." American Anthropologist 60 (1): 1-12.

Boyd, Robert, and Peter J. Richerson. 1985. Culture and the Evolutionary Process. Chicago: University of Chicago Press.

- 1988. "An Evolutionary Model of Social Learning: The Effects of Spatial and Temporal Variation.” In Social Learning: Psychological and Biological Perspectives, edited by Thomas R.

Zentall and Bennett G. Galef. Hillsdale, NJ: Lawrence Erlbaum Associates.

— 2010. "Transmission Coupling Mechanisms: Cultural Group Selection.” Philosophical 


\section{ON THE ORIGINS AND DESIGN OF WITCHES AND SORCERERS}

Transactions of the Royal Society of London. Series B, Biological Sciences 365 (1559): 3787-95. doi:10.1098/rstb.2010.0046.

Boyer, Pascal. 2001. Religion Explained: The Evolutionary Origins of Religious Thought. New York: Basic Books.

Boyer, Paul, and Stephen Nissenbaum. 1974. Salem Possessed: The Social Origins of Witchcraft. Cambridge, MA.

Bryant, A. T. 1929. Olden Times in Zululand and Natal. London: Longmans, Green and Co.

Budge, E. A. Wallis. 1901. Egyptian Magic. London: Kegan, Paul, Trech and Trübner \& Co. https://archive.org/details/EgyptianMagic_51.

Campbell, Donald T. 1965. "Variation and Selective Retention in Socio-Cultural Evolution." In Social Change in Developing Areas: A Reinterpretation of Evolutionary Theory, edited by Herbert R. Barringer, George Irving Blanksten, and Raymond Wright Mack, 19-49. Cambridge, Massachusetts: Schenkman Publishing Company.

Caporael, Linnda R. 1976. "Ergotism: The Satan Loosed in Salem?" Science 192 (4234): 21-26.

Chaudhuri, Soma. 2012. "Women as Easy Scapegoats: Witchcraft Accusations and Women as Targets in Tea Plantations of India." Violence Against Women 18 (10): 1213-34. doi:10.1177/1077801212465155.

Cohen, Stanley. 1972. Folk Devils and Moral Panics: The Creation of the Mods and Rockers. London: MacGibbon and Kee.

Cohn, Norman. 1966. "The Myth of the Jewish World-Conspiracy: A Case Study in Collective Psychopathology." Commentary 41 (6): 35-42.

- 1967. Warrant for Genocide: The Myth of the Jewish World-Conspiracy and the Protocols of the Elders of Zion. New York and Evanston: Harper \& Row.

- 1976. Europe's Inner Demons. Frogmore: Paladin.

Comaroff, Jean, and John L. Comaroff. 1999. "Occult Economies and the Violence of Abstraction: Notes from the South African Postcolony.” American Ethnologist 26 (2): 279303.

Cooper, Milton William. 1991. Behold a Pale Horse. Sedona, AZ: Light Technology Publishing. https://archive.org/details/WilliamCooperBeholdAPaleHorse1991.

Crawford, Jane. 1963. “Evidences for Witchcraft in Anglo-Saxon England.” Medium Evum 32 (2): 99-116.

Crick, Malcolm. 1973. "Two Styles in the Study of Witchcraft." Journal of the Anthropological Society of Oxford 4: 17-31.

De Laguna, Frederica. 1972. Under Mount Saint Elias: The History and Culture of the Yakutat Tlingit, Vol. 2. Washington, D.C.: Smithsonian Institution Press.

Debrunner, Hans W. 1961. Witchcraft in Ghana: A Study on the Belief in Destructive Witches and Its Effect on the Akan Tribes. Accra: Presbyterian Book Depot Ltd.

Desforges, Alison. 1999. Leave None to Tell the Story: Genocide in Rwanda. New York: Human Rights Watch.

Dundes, Alan, ed. 1992. The Evil Eye: A Casebook. Madison: The University of Wisconsin Press.

Emmons, George Thornton, and Frederica De Laguna. 1991. The Tlingit Indians.

Anthropological Papers of the American Museum of Natural History. Vol. 70. Seattle: University of Washington Press and the American Museum of Natural History.

http://digitallibrary.amnh.org/handle/2246/253.

Evans-Pritchard, E. E. 1937. Witchcraft, Oracles, and Magic among the Azande. Oxford, UK: 


\section{ON THE ORIGINS AND DESIGN OF WITCHES AND SORCERERS}

Clarendon Press.

Faulkingham, Ralph Harold. 1971. "Political Support in a Hausa Village.” Michigan State University.

Felix, Minucius, and Gerald H. Rendall. 1972. "Octavius." In Tertullian, Minucius Felix, edited by T. R. Glover and Gerald H. Rendall, 303-437. Cambridge: Harvard University Press. https://ryanfb.github.io/loebolus-data/L250.pdf.

Field, Margaret Joyce. 1970. Search for Security: An Ethno-Psychiatric Study of Rural Ghana. New York: W. W. Norton \& Company.

Firth, Raymond. 1954. "The Sociology of 'Magic' in Tikopia.” Sociologus 4 (2): 97-116.

Frazer, James George. 1920. The Golden Bough: A Study in Magic and Religion, Vol. 1 (The Magic Art and the Evolution of Kings, Vol. I). 2nd editio. London: Macmillan and Co.

https://archive.org/details/TheGoldenBough-Part1-

TheMagicArtAndTheEvolutionOfKingsVol.1.

Frazier, Brandy N., Susan A. Gelman, and Henry M. Wellman. 2009. "Preschoolers' Search for Explanatory Information within Adult-Child Conversation.” Child Development 80 (6): 1592-1611.

Galef, Bennett G., Kristina E. Dudley, and Elaine E. Whiskin. 2008. "Social Learning of Food Preferences in 'dissatisfied' and 'Uncertain' Norway Rats.” Animal Behaviour 75 (2): 631-37. doi:10.1016/j.anbehav.2007.06.024.

Gershman, Boris. 2016. "Witchcraft Beliefs and the Erosion of Social Capital: Evidence from Sub-Saharan Africa and Beyond." Journal of Development Economics 120. Elsevier B.V.: 182-208. doi:10.1016/j.jdeveco.2015.11.005.

Goode, Erich. 2008. "Moral Panics and Disproportionality: The Case of LSD Use in the Sixties." Deviant Behavior 29 (6): 533-43. doi:10.1080/01639620701839377.

Goode, Erich, and Nachman Ben-Yehuda. 2009. Moral Panics: The Social Construction of Deviance. 2nd ed. Wiley-Blackwell.

Gufler, H. 1999. "Witchcraft Beliefs among the Yamba (Cameroon)." Antbropos 94 (1-3): 18198. doi:10.2307/40465701.

Gusinde, Martin. 1971. The Fireland Indians, Vol. 1: The Selk'nam, on the Life and Thought of a Hunting People of the Great Island of Tierra Del Fuego. New Haven: Human Relations Area Files.

Haidt, Jonathan, Fredrik Björklund, and Scott Murphy. 2000. "Moral Dumbfounding: When Intuition Finds No Reason.”

http://faculty.virginia.edu/haidtlab/articles/manuscripts/haidt.bjorklund.workingpaper.when intuition finds no reason.pub603.doc.

Harman, Gilbert H. 1965. "The Inference to the Best Explanation.” The Philosophical Review 74 (1): 88-95.

Henrich, Joseph. 2015. The Secret of Our Success: How Culture Is Driving Human Evolution, Domesticating Our Species, and Making Us Smarter. Princeton, NJ: Princeton University Press.

Henry, Adam Hughes. 2014. "Polluting the Waters: A Brief History of Anti-Communist Propaganda during the Indonesian Massacres." Genocide Studies International 8 (2): 153-75. doi:10.3138/gsi.8.2.03.

Hester, Marianne. 1992. Lewd Women and Wicked Witches: A Study of the Dynamics of Male Domination. New York and London: Routledge. 


\section{ON THE ORIGINS AND DESIGN OF WITCHES AND SORCERERS}

Hoffman, Moshe, Erez Yoeli, and Martin A. Nowak. 2015. "Cooperate without Looking: Why We Care What People Think and Not Just What They Do." Proceedings of the National Academy of Sciences 112 (6): 1727-32. doi:10.1073/pnas.1417904112.

Hofstadter, Richard. 1964. "The Paranoid Style in American Politics.” Harper's Magazine. Hogbin, H. Ian. 1938. "Social Reaction to Crime: Law and Morals in the Schouten Islands, New Guinea." The Journal of the Royal Anthropological Institute of Great Britain and Ireland 68: $223-62$.

Hutton, Ronald. 2004. "Anthropological and Historical Approaches To Witchcraft: Potential for a New Collaboration?" The Historical Journal 47 (2): 413-34. doi:10.1017/S0018246X03003558.

- 2017. The Witch: A History of Fear, from Ancient Times Ot the Present. New Haven and London: Yale University Press.

Ivanow, W. 1926. "Muhammadan Child-Killing Demons." Man 26: 195-99.

Johnson, Dominic D. P., Daniel T Blumstein, James H Fowler, and Martie G Haselton. 2013. "The Evolution of Error: Error Management, Cognitive Constraints, and Adaptive Decision-Making Biases." Trends in Ecology E Evolution 28 (8). Elsevier Ltd: 474-81. doi:10.1016/j.tree.2013.05.014.

Johnson, Erik W., and Scott Frickel. 2011. "Ecological Threat and the Founding of U.S. National Environmental Movement Organizations, 1962-1998.” Social Problems 58 (3): 305-29. doi:10.1525/sp.2011.58.3.305.306.

Jones, William. 1939. Ethnography of the Fox Indians. Washington: Government Printing Office. Karlsen, Carol F. 1987. The Deril in the Shape of a Woman: Witchcraft in Colonial Nerw England. New York: W. W. Norton \& Company.

Karsten, Rafael. 1955. The Religion of the Samke: Ancient Beliefs and Cults of the Scandinavian and Finnish Lapps. Leiden: E.J. Brill. http://ehrafworldcultures.yale.edu/document?id=ep04005.

Keinan, G. 2002. "The Effects of Stress and Desire for Control on Superstitious Behavior." Personality and Social Psychology Bulletin 28 (1): 102-8. doi:10.1177/0146167202281009.

Kluckhohn, Clyde. 1944. Navaho Witchcraft.

- 1959. "Recurrent Themes in Myths and Mythmaking." Daedalus 88 (2): 268-79.

Knauft, Bruce. 2010. The Gebusi: Lives Transformed in a Rainforest World. 2nd Editio. New York: McGraw Hill.

Kunda, Ziva. 1990. “The Case for Motivated Reasoning." Psychological Bulletin 108 (3): 480-98. doi:10.1037/0033-2909.108.3.480.

Lagae, C. R. 1999. The Azande or Niam-Niam: Zande Organizations, Religious and Magical Beliefs, Family Customs. New Haven: HRAF.

Laland, Kevin N. 2004. "Social Learning Strategies." Learning \& Behaviour 32 (1): 4-14.

Lederman, Rena. 1981. "Sorcery and Social Change in Mendi." Social Analysis 8: 15-27.

Legare, Cristine H., and André L. Souza. 2012. "Evaluating Ritual Efficacy: Evidence from the Supernatural.” Cognition 124 (1): 1-15. doi:10.1016/j.cognition.2012.03.004.

Lombrozo, Tania. 2006. "The Structure and Function of Explanations." Trends in Cognitive Sciences 10 (10): 464-70. doi:10.1016/j.tics.2006.08.004.

Lonsdale, John. 1990. "Mau Maus of the Mind: Making Mau Mau and Remaking Kenya." The Journal of African History 31 (3): 393-421.

Mace, Ruth, Matthew G. Thomas, Jiajia Wu, QiaoQiao He, Ting Ji, and Yi Tao. 2018. 


\section{ON THE ORIGINS AND DESIGN OF WITCHES AND SORCERERS}

"Population Structured by Witchcraft Beliefs." Nature Human Behaviour 2 (1). Springer US: 39-44. doi:10.1038/s41562-017-0271-6.

Maher, Thomas V. 2010. "Threat, Resistance, and Collective Action: The Cases of Sobibór, Treblinka, and Auschwitz." American Sociological Review 75 (2): 252-72. doi:10.1177/0003122410365305.

Mair, Lucy. 1969. Witchcraft.

Malinowski, Bronisław. 1922. Argonauts of the Western Pacific: An Account of Native Enterprise and Adventure in the Archipelagoes of Melanesian New Guinea. London: George Routledge \& Sons, Ltd.

. 1948. "Magic, Science, and Religion." In Magic, Science and Religion, and Other Essays, 17-92. Garden City, NY: Doubleday Anchor Books.

Marshall, Lorna. 1962. "“!Kung Bushman Religious Beliefs." Africa 32 (3): 221-52.

Mashuri, Ali, and Esti Zaduqisti. 2015. "The Effect of Intergroup Threat and Social Identity Salience on the Belief in Conspiracy Theories over Terrorism in Indonesia: Collective Angst as a Mediator." International Journal of Psychological Research 8 (1): 24-35.

Massé, Henri, and Charles A. Messner. 1954. Persian Beliefs and Customs. New Haven: Human Relations Area Files.

McCauley, Clark, and Susan Jacques. 1979. "The Popularity of Conspiracy Theories of Presidential Assassination: A Bayesian Analysis." Journal of Personality and Social Psychology 37 (5): 637-44. doi:10.1037/0022-3514.37.5.637.

McKay, Ryan, and Charles Efferson. 2010. "The Subtleties of Error Management." Evolution and Human Behavior 31 (5). Elsevier Inc.: 309-19. doi:10.1016/j.evolhumbehav.2010.04.005.

Mercier, Hugo, and Dan Sperber. 2011. "Why Do Humans Reason? Arguments for an Argumentative Theory." Behavioral and Brain Sciences 34 (2): 57-74; discussion 74-111. doi:10.1017/S0140525X10000968.

Miceli, Maria, and Cristiano Castelfranchi. 2007. "The Envious Mind." Cognition and Emotion 21 (3): 449-79. doi:10.1080/02699930600814735.

Mirowsky, John, and Catherine E Ross. 1983. "Paranoia and the Structure of Powerlessness." American Sociological Review 48 (2): 228-39.

Morgan, Thomas J. H., Luke E. Rendell, Micael Ehn, William Hoppitt, and Kevin N. Laland. 2012. "The Evolutionary Basis of Human Social Learning." Proceedings of the Royal Society. Series B, Biological Sciences 279 (1729): 653-62. doi:10.1098/rspb.2011.1172.

Munro, Neil Gordon. 1963. Ainu Creed and Cult. New York: Columbia University Press.

Murray, Margaret Alice. 1921. The Witch Cult in Western Europe. Oxford: Clarendon Press. Nadel, Siegfried Frederick. 1954. Nupe Religion. London: Routledge \& Paul.

Natrella, Kayla Theresa. 2014. "Witchcraft and Women: A Historiography of Witchcraft as Gender History." Binghamton Journal of History 15. https://www.binghamton.edu/history/resources/journal-of-history/k-natrella.pdf.

Needham, Rodney. 1978. Primordial Characters. Charlottesville: University Press of Virginia.

Nemeroff, Carol, and Paul Rozin. 2000. "The Makings of the Magical Mind: The Nature and Function of Sympathetical Magical Thinking." In Imagining the Impossible: Magical, Scientific, and Religious Thinking in Children, 1-34. doi:10.1017/CBO9780511571381.002.

Nickerson, RS. 1998. "Confirmation Bias: A Ubiquitous Phenomenon in Many Guises." Review of General Psychology 2 (2): 175-220. doi:10.1037/1089-2680.2.2.175. 


\section{ON THE ORIGINS AND DESIGN OF WITCHES AND SORCERERS}

Norenzayan, Ara, Azim F. Shariff, Will M. Gervais, Aiyana K. Willard, Rita A. McNamara, Edward Slingerland, and Joseph Henrich. 2016. "The Cultural Evolution of Prosocial Religions." Behavioral and Brain Sciences 39: e1. doi:10.1017/S0140525X14001356.

Oliphant, Samuel Grant. 1913. "The Story of the Strix: Ancient." Transactions and Proceedings of the American Philological Association 44: 133-49.

- 1914. "The Story of the Strix: Isidorus and the Glossographers." Transactions and Proceedings of the American Philological Association 44: 49-63.

Oliver, Douglas L. 1955. A Solomon Island Society: Kinship And Leadership among the Siuai Of Bougainville. Harvard University Press.

Ono, Koichi. 1987. "Superstitious Behavior in Humans." Journal of the Experimental Analysis of Behavior 47 (3): 261-71. doi:10.1901/jeab.1987.47-261.

Oster, Emily. 2004. "Witchcraft, Weather and Economic Growth in Renaissance Europe." Journal of Economic Perspectives 18 (1): 215-28.

Parpola, Marjatta. 2000. Kerala Brahmins in Transition: A Study of a Namputiri Family. Helsinki: Finnish Oriental Society.

Pilling, Arnold Remington. 1958. "Law and Feud in an Aboriginal Society of North Australia." University of California, Berkeley.

Pospisil, Leopold J. 1958. Kapauku Papuans and Their Law. New Haven: Yale University:

Department of Anthropology.

Raihani, Nichola J, and Vaughan Bell. 2017. "Paranoia and the Social Representation of Others: A Large-Scale Game Theory Approach.” Scientific Reports 7. Springer US: 4544.

doi:10.1038/s41598-017-04805-3.

_. 2018. "An Evolutionary Perspective on Paranoia." Nature Human Behaviour. Springer US. doi:10.1038/s41562-018-0495-0.

Reichel-Dolmatoff, Gerardo. 1971. Amazonian Cosmos: The Sexual and Religious Symbolism of the Tukano Indians. Chicago: University of Chicago Press.

— 1976. "Training for the Priesthood among the Kogi of Colombia." In Enculturation in Latin America: An Anthology, 265-88. Los Angeles: UCLA Latin American Center

Publications.

-1997. The Kogi: A Tribe of the Sierra Nevada de Santa Marta, Colombia, Vol. 1. New Haven: HRAF.

Reynolds, Barrie. 1963. Magic, Divination and Witchcraft among the Barotse of Northern Rhodesia. London: Chatto and Windus.

Richards, Audrey I. 1935. “A Modern Movement of Witch-Finders.” Africa 8 (4): 448-61.

Rosnow, Ralph L. 1991. "Inside Rumor: A Personal Journey." American Psychologist 46 (5): 48496.

Rothschild, Zachary K, Mark J Landau, Daniel Sullivan, and Lucas A Keefer. 2012. "A DualMotive Model of Scapegoating : Displacing Blame to Reduce Guilt or Increase Control” 102 (6): 1148-63. doi:10.1037/a0027413.

Rozin, Paul, Linda Millman, and Carol Nemeroff. 1986. "Operation of the Laws of Sympathetic Magic in Disgust and Other Domains.” Journal of Personality and Social Psychology 50 (4): 703-12.

Rozin, Paul, and Carol Nemeroff. 2002. "Sympathetic Magical Thinking: The Contagion and Similarity 'Heuristics.” In Heuristics and Biases: The Psychology of Intuitive Judgment, edited by Thomas Gilovich, Dale Griffin, and Daniel Kahneman, 201-16. Cambridge, UK: 


\section{ON THE ORIGINS AND DESIGN OF WITCHES AND SORCERERS}

Cambridge University Press. doi:10.1017/CBO9780511808098.013.

Saalfeld, Vanessa, Zeina Ramadan, Vaughan Bell, and Nichola J. Raihani. 2018. "Differences in Social Rank and Political Affiliation Encourage Paranoid Attributions.”

https://psyarxiv.com/jxkv3/.

Sanders, Andrew. 1995. A Deed without a Name: The Witch in Society and History. Oxford and Washington DC: Berg Publishers.

Schapera, Isaac. 1952. "Sorcery and Witchcraft in Bechaunaland." African Affairs 51 (202): 4152.

Schnall, Simone, Jonathan Haidt, Gerald L. Clore, and Alexander H. Jordan. 2008. "Disgust as Embodied Moral Judgment." Personality and Social Psychology Bulletin 34 (8): 1096-1109. doi:10.1177/0146167208317771.

Singer, Andre. 1981. Witchcraft among the Azande. England: Royal Anthropological Institute.

Singh, Manvir. 2018. "The Cultural Evolution of Shamanism.” Behavioral and Brain Sciences 41: e66. doi:10.1017/S0140525X17001893.

Skaria, Ajay. 1997. "Women, Witchcraft and Gratuitous Violence in Colonial Western India." Past E Present 155: 109-41.

Smith, Richard H., and Sung Hee Kim. 2007. “Comprehending Envy.” Psychological Bulletin 133 (1): 46-64. doi:10.1037/0033-2909.133.1.46.

Smith, Richard H., Terence J. Turner, Ron Garonzik, Colin W. Leach, Vanessa Urch-Druskat, and Christine M. Weston. 1996. "Envy and Schadenfreude." Personality and Social Psychology Bulletin 22 (2): 158-68. doi:10.1177/0146167296222005.

Sperber, Dan. 1996. Explaining Culture: A Naturalistic Approach. Oxford, UK: Blackwell Publishers Ltd.

Sperber, Dan, Fabrice Clément, Christophe Heintz, Olivier Mascaro, Hugo Mercier, Gloria Origgi, and Deirdre Wilson. 2010. "Epistemic Vigilance.” Mind and Language 25 (4): 359_ 93. doi:10.1111/j.1468-0017.2010.01394.x.

Stern, Theodore. 1965. The Klamath Tribe: A People and Their Reservation. Seattle: University of Washington Press.

Sullivan, Daniel, Mark J Landau, Nyla R Branscombe, and Zachary K Rothschild. 2012. "Competitive Victimhood as a Response to Accusations of Ingroup Harm Doing." Journal of Personality and Social Psychology 102 (4): 778-95. doi:10.1037/a0026573.

Talayesva, Don C., and Leo William Simmons. 1942. Sun Chief: The Autobiography of a Hopi Indian. New Haven: Yale University Press.

Tennen, Howard, and Glenn Affleck. 1990. "Blaming Others for Threatening Events." Psychological Bulletin 108 (2): 209-32. doi:10.1037/0033-2909.108.2.209.

Tetlock, Philip E. 2003. "Thinking the Unthinkable: Sacred Values and Taboo Cognitions.” Trends in Cognitive Sciences 7 (7): 320-24. doi:10.1016/S1364-6613(03)00135-9.

Turner, Victor W. 1964. "Witchcraft and Sorcery: Taxonomy versus Dynamics." Africa 34 (4): 314-25.

van Bergen, Yfke, Isabelle Coolen, and Kevin N Laland. 2004. "Nine-Spined Sticklebacks Exploit the Most Reliable Source When Public and Private Information Conflict." Proceedings. Biological Sciences / The Royal Society 271 (1542): 957-62. doi:10.1098/rspb.2004.2684.

van de Ven, Niels, Charles E. Hoogland, Richard H. Smith, Wilco W. van Dijk, Seger M. Breugelmans, and Marcel Zeelenberg. 2015. "When Envy Leads to Schadenfreude." 


\section{ON THE ORIGINS AND DESIGN OF WITCHES AND SORCERERS}

Cognition and Emotion 29 (6). Taylor \& Francis: 1007-25. doi:10.1080/02699931.2014.961903.

van Prooijen, Jan-Willem, and Karen M. Douglas. 2017. "Conspiracy Theories as Part of History: The Role of Societal Crisis Situations.” Memory Studies 10 (3): 323-33. doi:10.1177/1750698017701615.

van Prooijen, Jan-Willem, and Nils B. Jostmann. 2013. "Belief in Conspiracy Theories: The Influence of Uncertainty and Perceived Morality." European Journal of Social Psychology 43 (1): 109-15. doi:10.1002/ejsp.1922.

van Prooijen, Jan-Willem, and Eric van Dijk. 2014. "When Consequence Size Predicts Belief in Conspiracy Theories: The Moderating Role of Perspective Taking." Journal of Experimental Social Psychology 55. Elsevier Inc.: 63-73. doi:10.1016/j.jesp.2014.06.006.

Victor, Jeffrey S. 1989. "A Rumor-Panic about a Dangerous Satanic Cult in Western New York." New York Folklore 15 (1-2): 23-49.

Vyse, Stuart. 2014. Believing in Magic: The Psychology of Superstition. Oxford and New York: Oxford University Press.

Walker, Jr., Deward E. 1967. "Nez Perce Sorcery.” Ethnology 6 (1): 66-96.

Wallace, Ernest, and E. Adamson Hoebel. 1952. The Comanches: Lords of the South Plains. Norman: University of Oklahoma Press.

Wallace, William J., and Edith S. Taylor. 1950. "Hupa Sorcery.” Southwestern Journal of Anthropology 6 (2): 188-96.

Walraven, B.C.A. 1980. "The Social Significance of Sorcery and Sorcery Accusations in Korea." Asiatische Studien: Zeitschrift Der Schweizerischen Asiengesellschaft 34 (2): 69-90.

Warner, W. Lloyd. 1958. A Black Civilization: A Social Study of an Australian Tribe. Harper \& Brothers.

Weltfish, Gene. 1965. The Lost Universe: With a Closing Chapter on "The Universe Regained." New York and London: Basic Books.

Whiting, Beatrice Blyth. 1950. Paiute Sorcery. New York: The Viking Fund Inc.

Wieringa, Saskia Eleonora. 2011. "Sexual Slander and the 1965/66 Mass Killings in Indonesia: Political and Methodological Considerations." Journal of Contemporary Asia 41 (4): 544-65. doi:10.1080/00472336.2011.610613.

Wilbert, Johannes. 1972. Survivors of Eldorado: Four Indian Cultures of South America. New York: Praeger Publishers.

Wilson, David Sloan. 2002. Darwin's Cathedral: Evolution, Religion, and the Nature of Society. Chicago: University of Chicago Press.

Wilson, Monica Hunter. 1951. "Witch Beliefs and Social Structure." American Journal of Sociology 56 (4): 307-13.

Wohl, Michael, and Nyla R. Branscombe. 2009. "Group Threat, Collective Angst, and Ingroup Forgiveness for the War in Iraq." Political Psychology 30 (2): 193-217. doi:10.1111/j.14679221.2008.00688.x. 


\title{
Magic, explanations, and evil \\ On the origins and design of witches and sorcerers
}

SUPPLEMENTARY MATERIAL

\author{
Manvir Singh
}

Last updated: 13 March 2020

\section{The Mystical Harm Survey (MHS)}

\subsection{Background}

The Mystical Harm Survey (MHS) is designed to characterize patterns in beliefs about practitioners of mystical harm across societies. It covers ethnographic texts from the 60 societies comprising the Probability Sample File of the electronic Human Relations Area Files, a pseudorandom sample of well-documented human societies designed to make inferences about humanity more generally (Human Relations Area Files 1967; Naroll 1967). For each society, I selected the two ethnographic texts containing the most paragraphs tagged for the code SORCERY (USE code 754) ${ }^{1}$. Whenever the documents included a total of less than twenty paragraphs, I included all ethnographic texts with paragraphs tagged for SORCERY until at least twenty paragraphs were covered or, if that was not possible, until all of the ethnographic texts tagged for SORCERY in a given culture were included.

Two independent coders read through the tagged paragraphs for each society, identified the different practitioners of mystical harm discussed, and coded each practitioner for 58 features. Discrepancies between the two resulting datasets were identified and resolved through discussion to produce a final, merged dataset, available at osf.io/492mj. Supplementary Table 1 displays the societies, ethnographic documents, and practitioner IDs.

\subsection{Inclusion criteria}

\footnotetext{
${ }^{1}$ According to the electronic Human Area Files, code 754 (SORCERY) includes any reference to the following: "Ideas of the causation of disease and death through witchcraft and sorcery; actual and reputed prevalence of sorcery; motives for practicing sorcery; methods (e.g., bone pointing, manipulation of effigies, exuvial magic, invocation of spirit aids); employment of sorcerers; witches, wizards, and sorcerers; physical, social and mental characteristics; sources of power; training; organization; special types of sorcerers (e.g., werewolves and other were-animals, vampires, individuals with the evil eye); evidence as to the efficacy of sorcery; reactions to sorcerers (e.g., witch hunts); etc."
} 
Each row of the dataset corresponds with a conception of a practitioner (or practice) of mystical harm. The original criteria for a practitioner of mystical harm were as follows (note that this passage has been edited slightly to make it more readable):

People who are believed to use magical or supernatural porvers to attack non-strangers: Individuals, either in-group or people with whom individuals otherwise frequently interact, believed to harm people they know through magic (e.g., recited spells, magical poisons, charms) or supernatural powers (e.g., becoming a spirit and eating people; transforming into animals and attacking people; harming people with thoughts or stares). This excludes beliefs about supernatural attackers who are strangers (e.g., beliefs that individuals from far-away lands transform into bears and hassle travelers). This also excludes people who only attack out-group members (e.g., shamans who only attack members of other groups).

Each row of the dataset refers to a different practitioner of mystical harm. Some societies have several such practitioners. For example, an ethnographer might describe one kind of person who can become an animal at night and a different kind of person who transmits harm through stares. In this instance, each practitioner is coded as a separate entry in the dataset. In another instance, an ethnographer may describe a single practitioner in a society, although that practitioner may have many abilities; for example, they may report that people believe that some individuals can become animals, fly, and attack with magical spells. In this instance, a single practitioner will appear in the dataset for that society.

Ethnographers may describe a technique or practice - for example, "black magic" - without connecting it to a certain practitioner. In these instances, rows in the dataset correspond only to the practice (when appropriate, variables CLASSO1 and CLASSO2 will add clarifying information).

Public magicians (e.g., shamans, priests, other magicians) are often said to have malignant, mystical powers. Whenever this is the case, coding is as follows:

- Whenever an ethnographer reports that a practitioner class includes, but is not restricted to, public magicians, then public magicians are not coded separately. For example, shamans are not coded separately if an ethnographer states that people believe that individuals in their group are witches and that shamans are sometimes accused as witches.

- Whenever an ethnographer reports that public magicians attack non-strangers with mystical powers and that they differ from other practitioner types on the basis of one or more variables, then they are coded separately. For example, shamans are coded separately if an ethnographer states that all witches harm people, but shaman-witches alone can fly and transform into animals.

Two additional exclusion criteria were added while resolving discrepancies:

Exclude: Spells and curses that are used to enforce contracts or promises

Exclude: Mystical harm that is considered to be "good magic", such as judiciary magic

\subsection{Citations}

Any coding decision that reports the presence of some trait includes a citation in the format ref $X: Y$, where $X$ refers to the number of the document (for example, reference 1 , reference 2 , and 
so on; the title and author of the document appear in the same row) and $Y$ refers to the page number.

\section{Analyses}

\subsection{Logistic PCA}

All statistical analyses were conducted in $\mathrm{R}$ ( $\mathrm{R}$ Core Team 2015). Because the data are binary, I conducted a logistic PCA, using the logisticPCA function of the logisticPCA package (Landgraf and Lee 2015). Following Landgraf (2016), I used the cv.lpca function to choose $m$, an argument in the logisticPCA function denoting the natural parameters from the saturated model.

I ran the model 10 times, varying $k$ from 1 to 10 , and produced a scree plot (see Supplementary Figure 1). The scree plot showed a break between the second and third components, justifying a cutoff either at two or three dimensions.

For the reported analyses, I excluded practitioner classes that are exclusively leaders (e.g., sheikhs, elders) and public magicians (e.g., shamans, priests) - that is, any practitioners coded 1 for the variable BEHA18. Note that the principal components are very similar regardless of whether these practitioner classes are included (compare the factor loadings in Supplementary Table 2 with those in Supplementary Table 4). I removed all free-response variables and transformed the following categorical variables into binary variables:

TECH10: $1 \& 2->1$

["always unintentional" and "sometimes unintentional" coded as "unintentional"]

PROC01: $1 \& 2->1$

["biological heredity" and "non-biological heredity" coded as "heredity"]

BEHA01: $1 \& 2-->1$

["devour flesh" and "devour souls" coded as "cannibalism"]

BEHA14: 1, 2, \& 3 --> $1 ; 4-->0$

["harm family members for enjoyment", "barm family members as obligation", and "barm family members as consequence of harm" coded as "barm family members"; "barm family members for other reasons" coded as absence]

BEHA20: $1 \& 2$--> 1

["political leaders" and "bousehold heads, elder lineages, generation leaders" coded as "leaders"]

I also created two new variables from the categorical variable SEX denoting whether the given practitioner class is mostly or exclusively female (SEX1) or mostly or exclusively male (SEX2). I binned each practice or practitioner class into a superordinate category (e.g., "evil eye", "witch") based on the ethnographer's translation (NAME02) and term (NAME03). The binning decisions are recorded under the variable NAME04 in the dataset.

The first two dimensions resulting from the logistic PCA are interpretable; the third dimension is not (see Supplementary Tables 2 and 3). I thus reported the first two dimensions and their corresponding loadings in the main text. I did not report loadings for any factor whose 
loading was driven entirely by a single geographic region (see next section and Supplementary Tables 5 and 6). Figure 1 in the main text shows the 83 practitioners plotted on the two principal components.

\subsection{Testing for geographic dependencies}

Some human societies are more similar to others, such as because they share a cultural history or because beliefs and practices have diffused from one to the other. Comparative analyses that investigate cross-cultural patterns must ensure that these non-independencies do not influence results and bias interpretations.

As I mentioned, I tried to minimize dependencies in the dataset by coding the Probability Sample File of the electronic Human Relations Area Files, a body of high-quality ethnography covering sixty societies that were chosen to represent human diversity and minimize similarities that might result from cultural diffusion or shared cultural history. But dependencies persist in the PSF, so I conducted two additional analyses to test whether geographic patterns in particular biased the results. First, I conducted an omnibus F-test to evaluate whether regions as defined by HRAF (e.g., Africa, Asia) have different PC scores on average. I found no evidence that they do $\left(F_{14,150}=1.66, p=0.070\right)$. Second, I re-ran the logistic PCA eight times, in each instance removing all of the data-points in a single region, and compared the resulting factor matrices. I found that the eight PCAs produced very similar components, despite using a substantially reduced dataset in some instances (removing Africa, for example, reduced the sample from 83 to 54 observations) (Supplementary Tables 5 and 6). Still, this analysis revealed that several variables, especially those with very few observations, were unstable across analyses, often with a factor loading collapsing when the observations for a single region were removed. I have shaded those loadings in Supplementary Tables 2 and 4 and refrained from reporting them in my description of the components in the main text.

\subsection{Testing for the stability of the principal components}

There is substantial disagreement about the appropriate sample size for principal component analysis, but I conducted several analyses to test whether the reported components are stable:

1. I produced jackknife estimates of the proportion of variance explained by the first two dimensions. The resampling procedure produced means nearly identical to the values reported above with very low variation $(\mathrm{k}=1$ : mean $=0.231$, $\mathrm{dd}=0.0026 ; \mathrm{k}=2$ : mean $=$ 0.400 , sd $=0.0030$ ), suggesting that, at the least, small deviations in sampling produce very similar components.

2. I re-ran the logistic PCA with the full MHS dataset, including leaders and public magicians. The factor matrix (Supplementary Table 4) is very similar to the factor matrix for the PCA with the reduced MHS dataset (Supplementary Table 2), suggesting not only that the sample size of 83 is sufficient to produce stable components but also that excluding institutionalized classes did not substantially bias the results of the PCA.

3. As I just described, I re-ran the logistic PCA eight times, in each instance removing all of the data-points in a single region. With the exception of several unstable loadings, which 
have been flagged, the resulting dimensions are highly stable and similar to those produced in the main analysis. 


\section{Supplementary Tables}

Supplementary Table 1. The sixty societies coded in the Mystical Harm Survey (MHS). The IDs denote the practices or practitioners coded and refer to the points in Figure 1 in the main article. Asterisks refer to leaders or public magicians believed to inflict mystical harm.

\begin{tabular}{|c|c|}
\hline $\begin{array}{c}\text { SOCIETY } \\
\text { (with references) }\end{array}$ & $\begin{array}{l}\text { PRACTITIONER } \\
\text { IDs }\end{array}$ \\
\hline Akan (Debrunner 1961; Field 1970) & 1,2 \\
\hline Amhara (Messing 1985; Reminick 1974) & 3 \\
\hline Andaman Islanders (Cipriani 1961; Man 1932) & $4^{*}$ \\
\hline Aranda (Basedow 1925; Spencer and Gillen 1927) & $5^{*}, 6,7$ \\
\hline Aymara (Tschopik 1946, 1951) & 8 \\
\hline Azande (Evans-Pritchard 1937; Lagae 1999) & $9,10,11,12,13$ \\
\hline Bahia Brazilians (Beierle 1999; Hutchinson 1957; Pierson 1967) & $14,15,16$ \\
\hline Bemba (Maxwell 1983; Richards 1935) & 17 \\
\hline Blackfoot (Goldfrank 1966; Schultz 1930) & 18 \\
\hline Bororo (Baldus and Lillios 1974; Colbacchini and Albisetti 1996) & $19^{*}, 20$ \\
\hline Central Thai (Hanks 1963; Textor 1973) & $21^{*}$ \\
\hline Chukchee (Bogoras 1907) & 22 \\
\hline Chuuk (Bollig 1967; Mahony 1971) & $23,24^{*}$ \\
\hline Copper Inuit (Damas 1996; Jenness 1922; Pryde 1972; Stefánsson 1913) & $25^{*}$ \\
\hline Dogon (Griaule and Winchell 1986; van Beek 1994) & $26,27,28$ \\
\hline Eastern Toraja (Adriani and Kruijt 1968, 1969) & $29,30,31$ \\
\hline Ganda (Mair 1934; Orley 1970) & 32,33 \\
\hline $\begin{array}{l}\text { Garo (Burling 1963; Goswami and Majudmar 1968; Majudmar 1978; Marak } \\
\text { 1997; Playfair 1909; Rongmuthu 1960) }\end{array}$ & $34^{*}, 35,36$ \\
\hline Guaraní (Ganson 1994; Schaden and Lewinsóhn 1969) & 37 \\
\hline Hausa (Besmer 1983; Cohen 1969; Faulkingham 1971; Greenberg 1946) & 38,39 \\
\hline Highland Scots (Ducey 1956; Geddes 1955; Parman 1990) & 40,41 \\
\hline Hopi (Aberle 1951; Talayesva and Simmons 1942) & 42 \\
\hline Iban (Graham 1987; Pilz 1988; Sandin 1967, 1980; Sutlive 1992) & 43 \\
\hline Ifugao (Barton 1919; Lambrecht 1955, 1957) & $44,45,46$ \\
\hline Iroquois (Parker 1913; Selden 1966; Wallace 1972) & $47,48^{*}$ \\
\hline Kanuri (Cohen 1967; Peshkin 1972) & $49,50,51^{*}$ \\
\hline Kapauku (Pospisil 1958, 1978) & 52,53 \\
\hline Khasi (Godwin-Austen 1872; McCormack 1964; Stegmiller and Knight 1956) & $54,55^{*}$ \\
\hline
\end{tabular}


Klamath (Gatschet 1890; Stern 1965)

Kogi

Korea

Kuna (Howe 1986; Marshall 1950; McKim 1947; Nordenskiöld 1930, 1966;

Nordenskiöld and Kantule 1938; Wafer 1934)

Kurds (Masters 1953)

Lau Fijians (Hocart 1929; St. Johnston 1918)

Libyan Bedouins (Abu-Lughod 1986)

Lozi (Gluckman 1955; Reynolds 1963)

Maasai (Merker 1971; Spencer 1988)

Mataco (Alvarsson 1988; Karsten 1932; Métraux 1943, 1959)

Mbuti (Turnbull 1965a, 1965b)

Ojibwa (Landes 1937; Rogers 1962)

Ona (Chapman 1982; Gusinde 1971)

Pawnee (Murie 1914; Weltfish 1965)

Saami (Itkonen 1984; Scheffer 1704)

Santal (Archer 1974, 1984)

Saramaka (Herskovits 1934; Price 1990)

Serbs (Kemp 1935; Pavlovic 1973)

Shluh (Berque 1973; Hatt 1974; Hoffman 1967; Montagne 1973)

Sinhalese (Leach 1961; MacDougall 1971)

Somali (Cerulli 1959; Helander 1988; Lewis 1961, 1963)

Taiwan Hokkien (Ahern 1973, 1978; Diamond 1969; Gallin 1966; Harrell 1974; Saso 1974; Seaman 1981; Wolf and Huang 1980)

Tarahumara (Bennett 1935; Kennedy 1978; Merrill 1988)

Tikopia (Firth 1939, 1954, 1970)

Tiv (Akiga and East 1939; Bohannan and Bohannan 1969)

Tlingit (De Laguna 1972; Emmons and De Laguna 1991)

Trobriand Islanders (Malinowski 1922; Tambiah 1983)

Tukano (Goldman 1963; Reichel-Dolmatoff 1971)

Tzeltal (Hunt 1962; Nash 1970)

Wolof (Ames 1959; Irvine 1973)

Yakut (Sieroszewski 1993)

Yanoama (Barker 1967; Chagnon 1968; Early and Peters 1990; Wilbert 1995)

$56^{*}$

No practitioners coded

No practitioners coded $57^{*}, 58^{*}, 59$

60

61,62

63

64

$65,66^{*}, 67$

68

69, 70

71,72

$73^{*}$

74

$75^{*}$

76,77

78

$79,80,81$

82

83,84

$85^{*}, 86,87$

88

89

90

91

92, 93

$94,95^{*}$

$96^{*}, 97,98$

99,100

101

$102 *$

103 
Supplementary Table 2. Factor matrix for main PCA; k=2. Loading values that exceed 0.1 are shaded in blue; those less than -0.1 are shaded in red. Lighter shades of blue or red are used whenever a loading is unstable (i.e., the loading approaches 0 when re-running the PCA without data-points in one of the eight world regions; see Supplementary Tables 5 and 6). See section 2 in the main text and section 2.1 in the Supplementary Materials for details.

\begin{tabular}{|c|c|c|c|}
\hline VARIABLE & DESCRIPTION & $\begin{array}{c}\text { LOADINGS } \\
(\mathrm{PC} 1)\end{array}$ & $\begin{array}{c}\text { LOADINGS } \\
\text { (PC2) }\end{array}$ \\
\hline ABIL01 & Fly & 0.32516907 & 0.14302452 \\
\hline ABIL02 & Invisibility & 0.205909888 & -0.009169168 \\
\hline ABIL03 & Soul travel & 0.056690138 & 0.033021234 \\
\hline ABIL04 & Animal transformation & 0.122242946 & 0.068753986 \\
\hline BEHA01 & Cannibalism & 0.103315857 & 0.128334064 \\
\hline BEHA02 & Corpse desecration & 0.121359352 & -0.082833927 \\
\hline BEHA03 & Opposite actions & 0.281345231 & 0.265918042 \\
\hline BEHA05 & Incest & 0.147052238 & -0.264364818 \\
\hline BEHA06 & Necrophilia & 0.33462192 & -0.176723353 \\
\hline BEHA07 & Nymphomania & 0.34353687 & 0.006144635 \\
\hline BEHA08 & Sexual obscenities for transformation & 0.086421939 & -0.291125273 \\
\hline BEHA09 & Nudity & 0.102146631 & 0.08326658 \\
\hline BEHA10 & Bad hygiene & 0.034940439 & 0.026754025 \\
\hline BEHA11 & Association with excretion & 0.039858256 & 0.017601684 \\
\hline BEHA12 & Conspiracy, league, organization & 0.138475056 & 0.019830117 \\
\hline BEHA13 & Meet in secret & 0.154627629 & 0.052992401 \\
\hline BEHA14 & Harm family members & 0.078032123 & 0.0011897 \\
\hline BEHA15 & Nighttime activity & 0.249260101 & 0.08622003 \\
\hline BEHA16 & Animal familiars & 0.118117498 & -0.000942145 \\
\hline BEHA19 & Magicians & 0.1592915 & -0.319589474 \\
\hline BEHA20 & Political leaders & 0.055161044 & -0.064466745 \\
\hline CLASS01 & All people capable & -0.146136104 & -0.244239998 \\
\hline CLASSO2 & Unspecified who does harm & -0.250167558 & -0.146828521 \\
\hline PHYS01 & Physiological differences & 0.052933539 & 0.232937982 \\
\hline PHYS03 & Phys. differences enable powers & 0.009980626 & 0.2803895 \\
\hline PHYS04 & Possession & 0.060299393 & 0.004828253 \\
\hline PHYS05 & Other differences & 0.036192844 & 0.074111038 \\
\hline PROC01 & Hereditary & 0.07217096 & 0.071607907 \\
\hline PROC02 & Inborn powers & -0.018598541 & 0.195605675 \\
\hline PROC03 & Learn powers & 0.105701039 & -0.079974362 \\
\hline PROC04 & Consume substance to gain powers & 0.068185729 & 0.115230135 \\
\hline PROC05 & Kill someone to gain powers & 0.083552187 & -0.049751624 \\
\hline PROC06 & Work with spirit & 0.031419489 & -0.062361694 \\
\hline
\end{tabular}




\begin{tabular}{c|l} 
PROC07 & Self-denial \\
SEX1 & Females \\
SEX2 & Males \\
TECH01 & Kill \\
TECH02 & Injure/cause illness \\
TECH03 & Cause sterility \\
TECH04 & Influence love \\
TECH05 & Cause economic harm \\
TECH06 & Cause catastrophe \\
TECH07 & Attack out-group members \\
TECH08 & Cause other harm \\
TECH10 & Unintentional harm \\
TECH11 & Evil eye/blasting word \\
TECH12 & Spells, charms, material magic \\
TECH13 & People pay practitioner \\
TECH14 & Attack with thoughts
\end{tabular}

\begin{tabular}{|l|l|}
-0.050628603 & -0.162398126 \\
0.02358944 & 0.05692325 \\
-0.006154369 & -0.130694118 \\
0.270335279 & 0.001278266 \\
0.177113799 & -0.018420366 \\
0.051593471 & 0.013879334 \\
0.038732201 & -0.030082982 \\
0.027404997 & 0.00280285 \\
0.085194669 & -0.01350542 \\
0.023585796 & -0.260215976 \\
0.036128341 & 0.006527775 \\
-0.028071652 & 0.183714785 \\
-0.049015075 & 0.116455603 \\
0.211641972 & -0.335998449 \\
0.08803222 & -0.054815857 \\
0.068173884 & 0.021752934
\end{tabular}


Supplementary Table 3. Factor matrix for main PCA; $k=3$. Note that the logistic PCA produces different principal components depending on the value of $k$. Loading values that exceed 0.1 are shaded in blue; those less than -0.1 are shaded in red. Variables with unstable loadings (see section 2.2 in the Supplementary Materials) are shaded in gray.

\begin{tabular}{|c|c|c|c|c|}
\hline VARIABLE & DESCRIPTION & $\begin{array}{l}\text { LOADINGS } \\
(\mathrm{PC} 1)\end{array}$ & $\begin{array}{c}\text { LOADINGS } \\
(\text { PC2) }\end{array}$ & $\begin{array}{c}\text { LOADINGS } \\
\text { (PC3) }\end{array}$ \\
\hline ABIL01 & Fly & 0.261310321 & 0.101815617 & -0.201846378 \\
\hline ABIL02 & Invisibility & 0.409703525 & -0.09070882 & 0.180670872 \\
\hline ABIL03 & Soul travel & 0.071268067 & 0.030519718 & 0.04431291 \\
\hline ABIL04 & Animal transformation & 0.119487455 & 0.056538577 & -0.026263067 \\
\hline BEHA01 & Cannibalism & 0.153564276 & 0.152742408 & 0.051352952 \\
\hline BEHA02 & Corpse desecration & 0.12080023 & -0.1122753 & -0.052821421 \\
\hline BEHA03 & Opposite actions & 0.310724617 & 0.252884327 & 0.046453642 \\
\hline BEHA05 & Incest & 0.080762048 & -0.241630038 & -0.091354863 \\
\hline BEHA06 & Necrophilia & 0.181585866 & -0.23391196 & -0.210422819 \\
\hline BEHA07 & Nymphomania & 0.115152046 & 0.024315248 & -0.23114178 \\
\hline BEHA08 & Sexual obscenities for transformation & 0.108406361 & -0.195815521 & 0.116101125 \\
\hline BEHA09 & Nudity & 0.091572631 & 0.0873964 & -0.096798347 \\
\hline BEHA10 & Bad hygiene & 0.044302125 & 0.022824908 & 0.10176039 \\
\hline BEHA11 & Association with excretion & 0.044741576 & 0.001787086 & -0.002544706 \\
\hline BEHA12 & Conspiracy, league, organization & 0.17365596 & -0.008798663 & -0.204633806 \\
\hline BEHA13 & Meet in secret & 0.162595738 & 0.034531167 & -0.052372707 \\
\hline BEHA14 & Harm family members & 0.071465612 & -0.00815942 & -0.047999928 \\
\hline BEHA15 & Nighttime activity & 0.281045093 & 0.080658594 & 0.109445833 \\
\hline BEHA16 & Animal familiars & 0.124565927 & -0.007817369 & 0.025785961 \\
\hline BEHA19 & Magicians & 0.121134907 & -0.31346491 & -0.043594339 \\
\hline BEHA20 & Political leaders & 0.052265438 & -0.07190035 & 0.005977858 \\
\hline CLASS01 & All people capable & -0.223463755 & -0.237884005 & 0.285994857 \\
\hline CLASSO2 & Unspecified who does harm & -0.231406022 & -0.114906425 & -0.155647345 \\
\hline PHYS01 & Physiological differences & 0.04683958 & 0.218749501 & -0.058742026 \\
\hline PHYS03 & Phys. differences enable powers & 0.036536654 & 0.273892194 & 0.015797165 \\
\hline PHYSO4 & Possession & 0.051172622 & 0.00496581 & -0.053254519 \\
\hline PHYS05 & Other differences & 0.04498602 & 0.072057847 & 0.009876187 \\
\hline PROC01 & Hereditary & 0.089410421 & 0.065727736 & 0.034238935 \\
\hline PROC02 & Inborn powers & 0.019420081 & 0.185572523 & 0.12565599 \\
\hline PROC03 & Learn powers & 0.228821394 & -0.153137777 & 0.261224069 \\
\hline PROC04 & Consume substance to gain powers & 0.083781038 & 0.127130635 & -0.023132067 \\
\hline PROC05 & Kill someone to gain powers & 0.081128883 & -0.062608431 & -0.001528838 \\
\hline PROC06 & Work with spirit & 0.021399866 & -0.056104371 & 0.020183767 \\
\hline PROC07 & Self-denial & -0.026746541 & -0.019501283 & 0.29936995 \\
\hline
\end{tabular}




\begin{tabular}{c|l} 
SEX1 & Females \\
SEX2 & Males \\
TECH01 & Kill \\
TECH02 & Injure/cause illness \\
TECH03 & Cause sterility \\
TECH04 & Influence love \\
TECH05 & Cause economic harm \\
TECH06 & Cause catastrophe \\
TECH07 & Attack out-group members \\
TECH08 & Cause other harm \\
TECH10 & Unintentional harm \\
TECH11 & Evil eye/blasting word \\
TECH12 & Spells, charms, material magic \\
TECH13 & People pay practitioner \\
TECH14 & Attack with thoughts
\end{tabular}

\begin{tabular}{|l|l|l|}
-0.050390224 & 0.202456316 & -0.370954747 \\
-0.016977207 & -0.122842641 & 0.047912838 \\
0.272269589 & -0.035747559 & 0.017591199 \\
0.177790256 & -0.018873235 & -0.07701598 \\
0.045053583 & 0.015378214 & -0.062798915 \\
0.034943364 & -0.035515646 & -0.019888074 \\
0.094707008 & -0.020996145 & 0.453659122 \\
0.080095645 & -0.019836153 & 0.001666995 \\
-0.022017348 & -0.319410645 & -0.097703912 \\
0.038735278 & 0.00038124 & 0.02299223 \\
0.008195979 & 0.174330917 & 0.156955982 \\
-0.028592515 & 0.10382641 & 0.072824517 \\
0.169514626 & -0.339638019 & -0.175331041 \\
0.082383068 & -0.059466278 & 0.012172597 \\
0.080965544 & 0.005891889 & -0.000470779
\end{tabular}


Supplementary Table 4. Factor matrix for PCA when including leaders and public magicians; $\mathrm{k}$ $=2$. The first PC was flipped (factor loadings were multiplied by -1) to make it comparable to the PCs shown in Supplementary Tables 2 and 3. Loading values that exceed 0.1 are shaded in blue; those less than -0.1 are shaded in red. Lighter shades of blue or red are used whenever a loading is likely to be unstable (see section 2.2 in the Supplementary Materials and Supplementary Tables 5 and 6).

\begin{tabular}{|c|c|c|c|}
\hline VARIABLE & DESCRIPTION & $\begin{array}{c}\text { LOADINGS } \\
\text { (PC1) }\end{array}$ & $\begin{array}{c}\text { LOADINGS } \\
(\mathrm{PC} 2)\end{array}$ \\
\hline ABIL01 & Fly & 0.312932832 & 0.150452661 \\
\hline ABIL02 & Invisibility & 0.139671194 & -0.061132521 \\
\hline ABIL03 & Soul travel & 0.059654541 & 0.034065482 \\
\hline ABIL04 & Animal transformation & 0.112058867 & 0.060849166 \\
\hline BEHA01 & Cannibalism & 0.094850787 & 0.147224247 \\
\hline BEHA02 & Corpse desecration & 0.131118907 & -0.089953239 \\
\hline BEHA03 & Opposite actions & 0.219594662 & 0.373463208 \\
\hline BEHA05 & Incest & 0.167292836 & -0.307183159 \\
\hline BEHA06 & Necrophilia & 0.368757815 & -0.211129435 \\
\hline BEHA07 & Nymphomania & 0.384224961 & 0.005063995 \\
\hline BEHA08 & Sexual obscenities for transformation & 0.092059453 & -0.356128452 \\
\hline BEHA09 & Nudity & 0.11628465 & 0.105273768 \\
\hline BEHA10 & Bad hygiene & 0.034889771 & 0.034530096 \\
\hline BEHA11 & Association with excretion & 0.041458222 & 0.025661462 \\
\hline BEHA12 & Conspiracy, league, organization & 0.115818639 & 0.016503716 \\
\hline BEHA13 & Meet in secret & 0.134499522 & 0.059533441 \\
\hline BEHA14 & Harm family members & 0.082464792 & 0.001235027 \\
\hline BEHA15 & Nighttime activity & 0.28572701 & 0.119801377 \\
\hline BEHA16 & Animal familiars & 0.125248313 & 0.003053012 \\
\hline BEHA19 & Magicians & 0.131307225 & -0.271205732 \\
\hline BEHA20 & Political leaders & 0.040163542 & -0.059802318 \\
\hline CLASS01 & All people capable & -0.113314878 & -0.24511333 \\
\hline CLASS02 & Unspecified who does harm & -0.265927537 & -0.177547625 \\
\hline PHYS01 & Physiological differences & 0.046404197 & 0.139929013 \\
\hline PHYS03 & Phys. differences enable powers & 0.030134315 & 0.117287614 \\
\hline PHYS04 & Possession & 0.053450375 & 0.011953868 \\
\hline PHYS05 & Other differences & 0.044383839 & 0.036624372 \\
\hline PROC01 & Hereditary & 0.073866425 & 0.077017831 \\
\hline PROC02 & Inborn powers & -0.010528638 & 0.203671599 \\
\hline PROC03 & Learn powers & 0.115663249 & -0.096759625 \\
\hline PROC04 & Consume substance to gain powers & 0.073834959 & 0.133829938 \\
\hline PROC05 & Kill someone to gain powers & 0.091385668 & -0.05587827 \\
\hline
\end{tabular}




\begin{tabular}{c|l} 
PROC06 & Work with spirit \\
PROC07 & Self-denial \\
SEX1 & Females \\
SEX2 & Males \\
TECH01 & Kill \\
TECH02 & Injure/cause illness \\
TECH03 & Cause sterility \\
TECH04 & Influence love \\
TECH05 & Cause economic harm \\
TECH06 & Cause catastrophe \\
TECH07 & Attack out-group members \\
TECH08 & Cause other harm \\
TECH10 & Unintentional harm \\
TECH11 & Evil eye/blasting word \\
TECH12 & Spells, charms, material magic \\
TECH13 & People pay practitioner \\
TECH14 & Attack with thoughts
\end{tabular}

\begin{tabular}{|l|l|}
0.031828357 & -0.043670455 \\
0.039799114 & -0.176563109 \\
0.020079901 & 0.074343695 \\
0.017071117 & -0.159396295 \\
0.273974326 & 0.017403458 \\
0.191232124 & -0.026061077 \\
0.046118629 & 0.021921333 \\
0.03533839 & -0.038463531 \\
0.027617601 & 0.018021146 \\
0.086925475 & -0.000474426 \\
0.021582662 & -0.156680262 \\
0.037868411 & 0.013103683 \\
-0.034699648 & 0.202230195 \\
-0.048879509 & 0.123233424 \\
0.176774225 & -0.254119465 \\
0.103091852 & -0.08334272 \\
0.05328259 & 0.040583132 \\
\hline
\end{tabular}


Supplementary Table 5. Factor loadings for PC1 for eight PCAs; all analyses excluded leaders and public magicians. For each PCA, all of the data for a single region were removed (e.g., the AFRICA column includes factors loadings for the PCA when excluding all of the data-points in Africa). Whenever necessary, PCs were flipped (factor loadings were multiplied by -1) to make them comparable to each other and to those shown in Supplementary Tables 2, 3, and 4. Loading values that exceed 0.1 are shaded in blue; those less than -0.1 are shaded in red. The coloring of the standard deviations corresponds with their values, ranging from white $(\mathrm{sd}=0)$ to green $(\mathrm{sd}=0.15)$. Factor loadings for PC2 appear in Supplementary Table 6.

\begin{tabular}{|c|c|c|c|c|c|c|c|c|c|c|c|}
\hline VAR & DESCRIPTION & AFRICA & ASIA & EUROPE & $\begin{array}{l}\text { MIDDLE } \\
\text { AMER. }\end{array}$ & $\begin{array}{l}\text { MIDDLE } \\
\text { EAST }\end{array}$ & $\begin{array}{l}\text { NORTH } \\
\text { AMER. }\end{array}$ & OCEAN. & $\begin{array}{l}\text { SOUTH } \\
\text { AMER. }\end{array}$ & MEAN & $\begin{array}{l}\text { STD } \\
\text { DEV }\end{array}$ \\
\hline ABIL01 & Fly & 0.277 & 0.457 & 0.290 & 0.325 & 0.344 & 0.209 & 0.296 & 0.298 & 0.312 & 0.071 \\
\hline ABIL02 & Invisibility & 0.150 & 0.083 & 0.391 & 0.203 & 0.166 & 0.092 & 0.119 & 0.182 & 0.173 & 0.098 \\
\hline ABIL03 & Soul travel & 0.056 & 0.051 & 0.075 & 0.057 & 0.051 & 0.058 & 0.067 & 0.050 & 0.058 & 0.009 \\
\hline ABIL04 & Animal transformation & 0.123 & 0.112 & 0.109 & 0.122 & 0.130 & 0.117 & 0.142 & 0.158 & 0.127 & 0.017 \\
\hline BEHA01 & Cannibalism & 0.089 & 0.108 & 0.184 & 0.104 & 0.103 & 0.113 & 0.082 & 0.095 & 0.110 & 0.032 \\
\hline ВЕНА02 & Corpse desecration & 0.125 & 0.107 & 0.109 & 0.121 & 0.117 & 0.138 & 0.213 & 0.055 & 0.123 & 0.044 \\
\hline ВЕНА03 & Opposite actions & 0.302 & 0.329 & 0.291 & 0.287 & 0.282 & 0.345 & 0.323 & 0.000 & 0.270 & 0.111 \\
\hline BEHA05 & Incest & 0.167 & 0.104 & 0.160 & 0.144 & 0.140 & 0.120 & 0.139 & 0.090 & 0.133 & 0.026 \\
\hline BEHA06 & Necrophilia & 0.359 & 0.277 & 0.001 & 0.332 & 0.332 & 0.298 & 0.365 & 0.267 & 0.279 & 0.118 \\
\hline BEHA07 & Nymphomania & 0.343 & 0.273 & 0.304 & 0.346 & 0.356 & 0.136 & 0.302 & 0.269 & 0.291 & 0.071 \\
\hline BEHA08 & $\begin{array}{l}\text { Sexual obscenities for } \\
\text { transformation }\end{array}$ & 0.111 & 0.045 & 0.160 & 0.084 & 0.089 & 0.088 & 0.122 & 0.000 & 0.088 & 0.048 \\
\hline BEHA09 & Nudity & 0.095 & 0.098 & 0.085 & 0.103 & 0.102 & 0.094 & 0.084 & 0.269 & 0.116 & 0.062 \\
\hline BEHA10 & Bad hygiene & 0.043 & 0.026 & 0.048 & 0.035 & 0.034 & 0.041 & 0.033 & 0.011 & 0.034 & 0.012 \\
\hline BEHA11 & Association with excretion & 0.036 & 0.046 & 0.089 & 0.039 & 0.041 & 0.037 & 0.034 & 0.000 & 0.040 & 0.024 \\
\hline BEHA12 & Conspiracy, league, organization & 0.136 & 0.129 & 0.109 & 0.139 & 0.143 & 0.129 & 0.126 & 0.343 & 0.157 & 0.076 \\
\hline BEHA13 & Meet in secret & 0.144 & 0.136 & 0.152 & 0.155 & 0.159 & 0.139 & 0.139 & 0.276 & 0.162 & 0.047 \\
\hline BEHA14 & Harm family members & 0.077 & 0.085 & 0.084 & 0.078 & 0.080 & 0.083 & 0.082 & 0.042 & 0.076 & 0.014 \\
\hline BEHA15 & Nighttime activity & 0.234 & 0.253 & 0.301 & 0.251 & 0.232 & 0.225 & 0.226 & 0.260 & 0.248 & 0.025 \\
\hline BEHA16 & Animal familiars & 0.113 & 0.151 & 0.128 & 0.118 & 0.109 & 0.119 & 0.127 & 0.097 & 0.120 & 0.016 \\
\hline BEHA19 & Magicians & 0.170 & 0.151 & 0.115 & 0.155 & 0.153 & 0.177 & 0.162 & 0.091 & 0.147 & 0.029 \\
\hline BEHA20 & Political leaders & 0.058 & 0.050 & 0.047 & 0.054 & 0.053 & 0.061 & 0.048 & 0.066 & 0.054 & 0.007 \\
\hline
\end{tabular}




\begin{tabular}{|c|c|c|c|c|c|c|c|c|c|c|c|}
\hline CLASS01 & All people capable & -0.118 & -0.146 & -0.148 & -0.154 & -0.170 & -0.188 & -0.160 & -0.121 & -0.150 & 0.024 \\
\hline CLASS02 & Unspecified who does harm & -0.243 & -0.260 & -0.224 & -0.254 & -0.235 & -0.217 & -0.260 & -0.301 & -0.249 & 0.027 \\
\hline PHYS01 & Physiological differences & 0.033 & 0.052 & 0.028 & 0.055 & 0.058 & 0.056 & 0.083 & 0.105 & 0.059 & 0.025 \\
\hline PHYS03 & Phys. differences enable powers & -0.013 & -0.014 & 0.016 & 0.013 & 0.023 & 0.010 & 0.032 & 0.041 & 0.014 & 0.020 \\
\hline PHYS04 & Possession & 0.057 & 0.067 & 0.065 & 0.060 & 0.061 & 0.054 & 0.056 & 0.058 & 0.060 & 0.005 \\
\hline PHYS05 & Other differences & 0.019 & 0.051 & 0.052 & 0.036 & 0.035 & 0.041 & 0.049 & 0.014 & 0.037 & 0.014 \\
\hline PROC01 & Hereditary & 0.065 & 0.072 & 0.078 & 0.073 & 0.070 & 0.086 & 0.075 & 0.074 & 0.074 & 0.006 \\
\hline PROC02 & Inborn powers & -0.040 & 0.010 & -0.011 & -0.012 & -0.048 & -0.008 & 0.003 & -0.015 & -0.015 & 0.020 \\
\hline PROC03 & Learn powers & 0.113 & 0.090 & 0.174 & 0.104 & 0.106 & 0.097 & 0.106 & 0.055 & 0.106 & 0.033 \\
\hline PROC04 & $\begin{array}{l}\text { Consume substance to gain } \\
\text { powers }\end{array}$ & 0.061 & 0.073 & 0.071 & 0.069 & 0.071 & 0.076 & 0.076 & 0.085 & 0.073 & 0.007 \\
\hline PROC05 & Kill someone to gain powers & 0.085 & 0.077 & 0.090 & 0.084 & 0.085 & 0.084 & 0.072 & 0.161 & 0.092 & 0.028 \\
\hline PROC06 & Work with spirit & 0.038 & 0.030 & 0.042 & 0.030 & 0.024 & 0.025 & 0.031 & 0.027 & 0.031 & 0.006 \\
\hline PROC07 & Self-denial & -0.040 & 0.001 & -0.020 & -0.053 & -0.049 & -0.069 & -0.059 & -0.060 & -0.044 & 0.023 \\
\hline SEX1 & Females & 0.017 & 0.022 & 0.020 & 0.024 & 0.035 & 0.022 & 0.015 & 0.035 & 0.024 & 0.007 \\
\hline SEX2 & Males & -0.003 & -0.005 & -0.004 & -0.008 & -0.008 & 0.000 & -0.004 & -0.051 & -0.010 & 0.017 \\
\hline ТЕCH01 & Kill & 0.304 & 0.275 & 0.245 & 0.268 & 0.268 & 0.273 & 0.270 & 0.273 & 0.272 & 0.016 \\
\hline TECH02 & Injure/cause illness & 0.162 & 0.163 & 0.186 & 0.176 & 0.198 & 0.208 & 0.149 & 0.221 & 0.183 & 0.025 \\
\hline ТЕCH03 & Cause sterility & 0.052 & 0.066 & 0.053 & 0.052 & 0.054 & 0.058 & 0.045 & 0.026 & 0.051 & 0.011 \\
\hline TECH04 & Influence love & 0.042 & 0.042 & 0.017 & 0.038 & 0.040 & 0.048 & 0.036 & 0.035 & 0.037 & 0.009 \\
\hline TECH05 & Cause economic harm & 0.025 & 0.034 & 0.037 & 0.027 & 0.023 & 0.029 & 0.041 & -0.007 & 0.026 & 0.015 \\
\hline TECH06 & Cause catastrophe & 0.086 & 0.096 & 0.088 & 0.085 & 0.087 & 0.103 & 0.074 & 0.065 & 0.086 & 0.012 \\
\hline ТЕCH07 & Attack out-group members & 0.060 & 0.016 & -0.015 & 0.021 & -0.003 & 0.069 & 0.025 & -0.046 & 0.016 & 0.038 \\
\hline TECH08 & Cause other harm & 0.033 & 0.044 & 0.037 & 0.036 & 0.033 & 0.048 & 0.043 & -0.008 & 0.033 & 0.017 \\
\hline TECH10 & Unintentional harm & -0.035 & -0.011 & -0.024 & -0.021 & -0.017 & -0.052 & -0.006 & -0.049 & -0.027 & 0.017 \\
\hline TECH11 & Evil eye/blasting word & -0.051 & -0.041 & -0.037 & -0.044 & -0.043 & -0.042 & -0.054 & -0.051 & -0.046 & 0.006 \\
\hline TECH12 & Spells, charms, material magic & 0.247 & 0.219 & 0.187 & 0.208 & 0.208 & 0.198 & 0.224 & 0.119 & 0.201 & 0.038 \\
\hline TECH13 & People pay practitioner & 0.092 & 0.078 & 0.083 & 0.087 & 0.085 & 0.085 & 0.080 & 0.076 & 0.083 & 0.005 \\
\hline TECH14 & Attack with thoughts & 0.064 & 0.073 & 0.077 & 0.068 & 0.066 & 0.421 & 0.068 & 0.011 & 0.106 & 0.129 \\
\hline
\end{tabular}


Supplementary Table 6. Factor loadings for PC2 for eight PCAs; all analyses excluded leaders and public magicians. For each PCA, all of the data for a single region were removed (e.g., the AFRICA column includes factors loadings for the PCA when excluding all of the data-points in Africa). Whenever necessary, PCs were flipped (factor loadings were multiplied by -1) to make them comparable to each other and to those shown in Supplementary Tables 2, 3, and 4. Loading values that exceed 0.1 are shaded in blue; those less than -0.1 are shaded in red. The coloring of the standard deviations corresponds with their values, ranging from white $(\mathrm{sd}=0)$ to green $(\mathrm{sd}=0.15)$. Factor loadings for PC1 appear in Supplementary Table 6.

\begin{tabular}{|c|c|c|c|c|c|c|c|c|c|c|c|}
\hline VAR & DESCRIPTION & AFRICA & ASIA & EUROPE & $\begin{array}{c}\text { MIDDLE } \\
\text { AMER. }\end{array}$ & $\begin{array}{c}\text { MIDDLE } \\
\text { EAST }\end{array}$ & $\begin{array}{c}\text { NORTH } \\
\text { AMER. }\end{array}$ & OCEAN. & $\begin{array}{l}\text { SOUTH } \\
\text { AMER. }\end{array}$ & MEAN & $\begin{array}{l}\text { STD } \\
\text { DEV }\end{array}$ \\
\hline ABIL01 & Fly & 0.158 & 0.139 & 0.201 & 0.138 & 0.123 & 0.117 & 0.169 & 0.084 & 0.141 & 0.036 \\
\hline ABIL02 & Invisibility & 0.002 & -0.027 & -0.117 & -0.013 & -0.012 & -0.002 & -0.011 & 0.141 & -0.005 & 0.070 \\
\hline ABIL03 & Soul travel & 0.043 & 0.029 & 0.006 & 0.033 & 0.052 & 0.031 & 0.028 & 0.015 & 0.030 & 0.014 \\
\hline ABIL04 & Animal transformation & 0.079 & 0.049 & 0.057 & 0.067 & 0.063 & 0.072 & 0.087 & 0.074 & 0.069 & 0.012 \\
\hline BEHA01 & Cannibalism & 0.127 & 0.132 & 0.130 & 0.129 & 0.169 & 0.137 & 0.095 & 0.084 & 0.125 & 0.026 \\
\hline BEHA02 & Corpse desecration & -0.065 & -0.076 & -0.088 & -0.085 & -0.081 & -0.088 & -0.135 & -0.089 & -0.088 & 0.020 \\
\hline BEHA03 & Opposite actions & 0.272 & 0.238 & 0.238 & 0.264 & 0.262 & 0.218 & 0.251 & 0.000 & 0.218 & 0.090 \\
\hline BEHA05 & Incest & -0.257 & -0.339 & -0.287 & -0.262 & -0.258 & -0.166 & -0.197 & -0.045 & -0.226 & 0.090 \\
\hline BEHA06 & Necrophilia & -0.157 & -0.221 & 0.000 & -0.178 & -0.161 & -0.141 & -0.151 & -0.121 & -0.141 & 0.064 \\
\hline BEHA07 & Nymphomania & 0.020 & -0.055 & -0.012 & 0.000 & -0.006 & -0.009 & -0.021 & 0.130 & 0.006 & 0.054 \\
\hline BEHA08 & $\begin{array}{l}\text { Sexual obscenities for } \\
\text { transformation }\end{array}$ & -0.307 & -0.300 & -0.287 & -0.294 & -0.276 & -0.314 & -0.316 & 0.000 & -0.262 & 0.106 \\
\hline BEHA09 & Nudity & 0.092 & 0.064 & 0.081 & 0.083 & 0.076 & 0.080 & 0.082 & 0.130 & 0.086 & 0.020 \\
\hline BEHA10 & Bad hygiene & 0.014 & 0.079 & 0.005 & 0.027 & 0.025 & 0.022 & 0.022 & -0.015 & 0.022 & 0.027 \\
\hline BEHA11 & Association with excretion & 0.015 & 0.012 & -0.028 & 0.018 & 0.012 & 0.024 & 0.015 & 0.000 & 0.008 & 0.016 \\
\hline BEHA12 & Conspiracy, league, organization & 0.030 & 0.005 & 0.040 & 0.018 & 0.012 & 0.026 & 0.039 & -0.102 & 0.008 & 0.046 \\
\hline BEHA13 & Meet in secret & 0.059 & 0.037 & 0.066 & 0.051 & 0.043 & 0.063 & 0.074 & -0.079 & 0.039 & 0.049 \\
\hline BEHA14 & Harm family members & 0.005 & 0.000 & 0.013 & 0.000 & -0.004 & 0.006 & 0.004 & -0.030 & -0.001 & 0.013 \\
\hline BEHA15 & Nighttime activity & 0.097 & 0.103 & 0.080 & 0.084 & 0.077 & 0.082 & 0.069 & 0.006 & 0.075 & 0.030 \\
\hline BEHA16 & Animal familiars & -0.001 & -0.003 & -0.006 & -0.002 & 0.006 & 0.006 & -0.024 & 0.000 & -0.003 & 0.009 \\
\hline BEHA19 & Magicians & -0.266 & -0.341 & -0.260 & -0.323 & -0.336 & -0.320 & -0.254 & -0.448 & -0.319 & 0.063 \\
\hline BEHA20 & Political leaders & -0.057 & -0.049 & -0.051 & -0.065 & -0.068 & -0.059 & -0.060 & -0.379 & -0.099 & 0.114 \\
\hline
\end{tabular}




\begin{tabular}{|c|c|c|c|c|c|c|c|c|c|c|c|}
\hline CLASS01 & All people capable & -0.278 & -0.157 & -0.263 & -0.246 & -0.238 & -0.282 & -0.262 & -0.160 & -0.236 & 0.050 \\
\hline CLASS02 & Unspecified who does harm & -0.178 & -0.176 & -0.114 & -0.140 & -0.125 & -0.131 & -0.131 & -0.095 & -0.136 & 0.029 \\
\hline PHYS01 & Physiological differences & 0.238 & 0.201 & 0.298 & 0.235 & 0.209 & 0.221 & 0.261 & 0.245 & 0.239 & 0.031 \\
\hline PHYS03 & Phys. differences enable powers & 0.272 & 0.297 & 0.303 & 0.280 & 0.221 & 0.289 & 0.323 & 0.188 & 0.272 & 0.045 \\
\hline PHYS04 & Possession & 0.010 & -0.014 & 0.000 & 0.005 & 0.001 & 0.006 & 0.011 & 0.020 & 0.005 & 0.010 \\
\hline PHYS05 & Other differences & 0.129 & 0.074 & 0.051 & 0.075 & 0.082 & 0.072 & 0.047 & 0.069 & 0.075 & 0.025 \\
\hline PROC01 & Hereditary & 0.075 & 0.065 & 0.050 & 0.072 & 0.084 & 0.081 & 0.062 & 0.066 & 0.069 & 0.011 \\
\hline PROC02 & Inborn powers & 0.195 & 0.225 & 0.175 & 0.188 & 0.296 & 0.178 & 0.150 & 0.164 & 0.196 & 0.046 \\
\hline PROC03 & Learn powers & -0.068 & -0.078 & -0.155 & -0.081 & -0.080 & -0.073 & -0.076 & -0.076 & -0.086 & 0.028 \\
\hline PROC04 & $\begin{array}{l}\text { Consume substance to gain } \\
\text { powers }\end{array}$ & 0.127 & 0.111 & 0.085 & 0.115 & 0.123 & 0.115 & 0.082 & 0.211 & 0.121 & 0.040 \\
\hline PROC05 & Kill someone to gain powers & -0.048 & -0.052 & -0.062 & -0.052 & -0.056 & -0.047 & -0.061 & -0.116 & -0.062 & 0.023 \\
\hline PROC06 & Work with spirit & -0.073 & -0.052 & -0.083 & -0.062 & -0.059 & -0.061 & -0.061 & -0.050 & -0.063 & 0.011 \\
\hline PROC07 & Self-denial & -0.220 & 0.000 & -0.163 & -0.163 & -0.154 & -0.165 & -0.166 & -0.112 & -0.143 & 0.065 \\
\hline SEX1 & Females & 0.057 & 0.047 & 0.087 & 0.057 & 0.036 & 0.055 & 0.067 & 0.050 & 0.057 & 0.015 \\
\hline SEX2 & Males & -0.188 & -0.113 & -0.125 & -0.128 & -0.122 & -0.115 & -0.133 & -0.122 & -0.131 & 0.024 \\
\hline TECH01 & Kill & 0.012 & -0.007 & -0.017 & -0.011 & 0.003 & 0.002 & 0.001 & -0.031 & -0.006 & 0.014 \\
\hline TECH02 & Injure/cause illness & 0.013 & -0.021 & -0.016 & -0.028 & -0.029 & -0.015 & -0.076 & 0.007 & -0.021 & 0.027 \\
\hline TECH03 & Cause sterility & 0.025 & 0.013 & 0.010 & 0.013 & 0.009 & 0.014 & 0.020 & -0.009 & 0.012 & 0.010 \\
\hline TECH04 & Influence love & -0.024 & -0.043 & -0.015 & -0.030 & -0.031 & -0.032 & -0.017 & -0.031 & -0.028 & 0.009 \\
\hline TECH05 & Cause economic harm & 0.003 & 0.022 & -0.013 & 0.004 & 0.006 & 0.003 & 0.003 & -0.035 & -0.001 & 0.017 \\
\hline TECH06 & Cause catastrophe & -0.010 & 0.013 & -0.024 & -0.015 & -0.017 & -0.026 & -0.013 & -0.058 & -0.019 & 0.020 \\
\hline TECH07 & Attack out-group members & -0.180 & -0.179 & -0.256 & -0.263 & -0.302 & -0.332 & -0.268 & -0.216 & -0.250 & 0.055 \\
\hline TECH08 & Cause other harm & 0.011 & 0.011 & 0.008 & 0.008 & 0.009 & 0.009 & 0.021 & -0.056 & 0.003 & 0.024 \\
\hline TECH10 & Unintentional harm & 0.174 & 0.177 & 0.179 & 0.175 & 0.154 & 0.238 & 0.215 & 0.144 & 0.182 & 0.031 \\
\hline TECH11 & Evil eye/blasting word & 0.099 & 0.118 & 0.102 & 0.112 & 0.106 & 0.112 & 0.104 & 0.183 & 0.117 & 0.027 \\
\hline TECH12 & Spells, charms, material magic & -0.312 & -0.361 & -0.322 & -0.343 & -0.328 & -0.333 & -0.357 & -0.397 & -0.344 & 0.027 \\
\hline TECH13 & People pay practitioner & -0.045 & -0.062 & -0.051 & -0.056 & -0.053 & -0.054 & -0.053 & -0.081 & -0.057 & 0.011 \\
\hline TECH14 & Attack with thoughts & 0.030 & 0.028 & 0.014 & 0.021 & 0.036 & -0.003 & 0.023 & -0.045 & 0.013 & 0.026 \\
\hline
\end{tabular}




\section{Supplementary Figure}

Supplementary Figure 1. Scree plot for main logistic PCA. Gray points show the additional variance explained by each principal component. Black points show the cumulative variance explained.

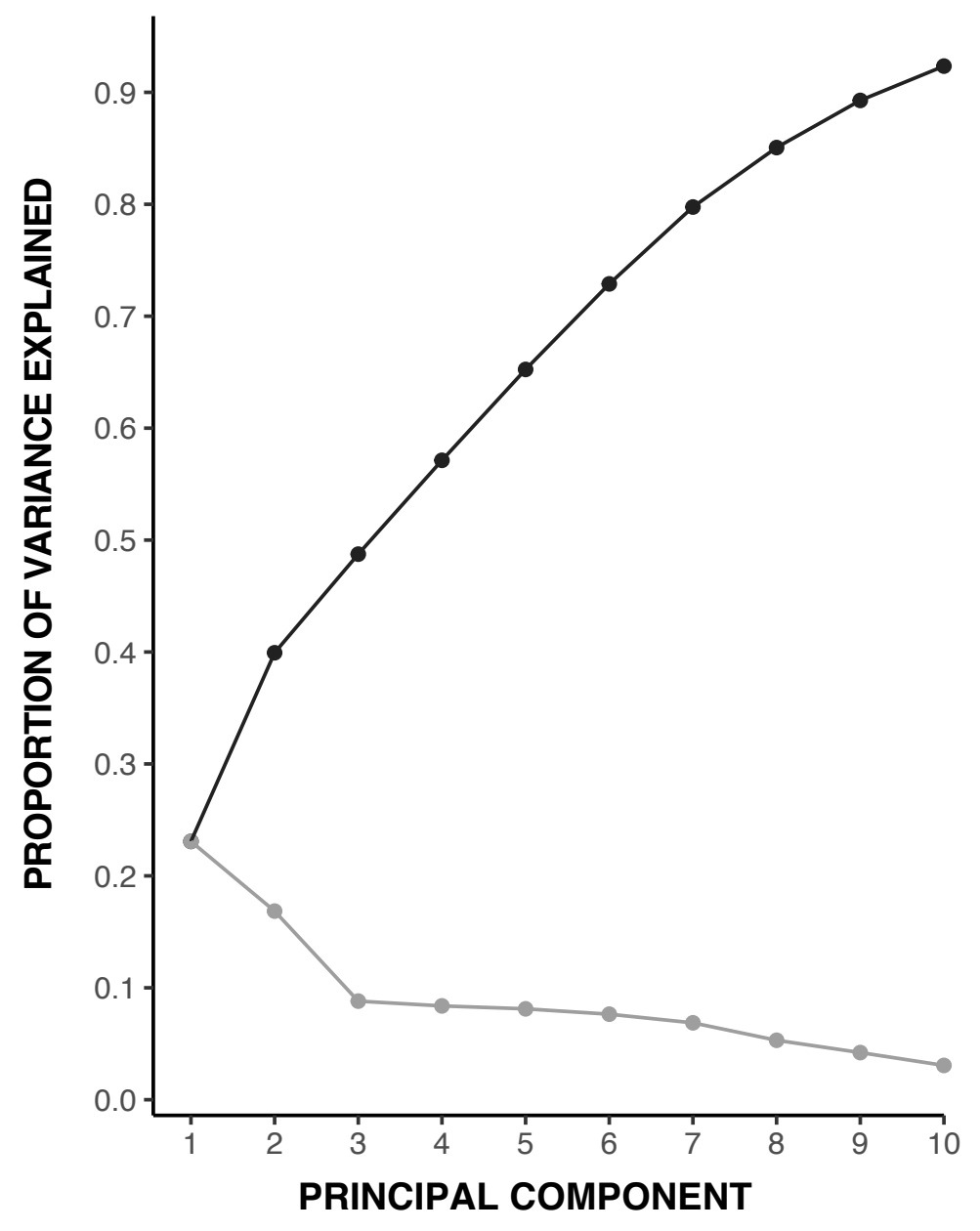




\section{References}

Aberle, D. F. (1951) The psychosocial analysis of a Hopi life-history. University of California Press. Abu-Lughod, L. (1986) Veiled sentiments: Honor and poetry in a Bedouin society. University of California Press.

Adriani, N., \& Kruijt, A. C. (1968) The Bare'e-speaking Toradja of central Celebes (the East Toradja), vol. 1. Human Relations Area Files.

Adriani, N., \& Kruijt, A. C. (1969) The Bare'e-speaking Toradja of central Celebes (the East Toradja), vol. 2. Human Relations Area Files.

Ahern, E. M. (1973) The cult of the dead in a Chinese village. Stanford University Press.

Ahern, E. M. (1978) The power and pollution of Chinese women. In: Studies in Chinese society ed. A. P. Wolf, pp. 269-290. Stanford University Press.

Akiga, \& East, R. (1939) Akiga's story: The Tiv tribe as seen by one of its members. Oxford University Press.

Alvarsson, J.A. (1988) The Mataco of the Gran Chaco: An ethnographic account of change and continuity in Mataco socio-economic organization. Academiae Upsaliensis.

Ames, D. (1959) Belief in "witches" among the rural Wolof of the Gambia. Africa 29:263-273.

Archer, W. G. (1974) The hill of flutes: Life, love, and poetry in tribal India : a portrait of the Santals. University of Pittsburgh Press.

Archer, W. G. (1984) Tribal law And justice: A report on the Santal. Concept.

Baldus, H., \& Lillios, I. (1974) The social position of the woman among the Eastern Bororo. Human Relations Area Files.

Barker, J. (1967) Memoir on the culture of the Waica. Human Relations Area Files.

Barton, R. F. (1919) Ifuago law. University of California Press. https://archive.org/details/ifugaolawroy00bartrich

Basedow, H. (1925) The Australian aboriginal. F. W. Preece and sons.

Beierle, J. (1999) Culture summary: Bahia Brazilians. HRAF.

Bennett, W. C. (1935) The Tarahumara: An Indian tribe of northern Mexico. The University of Chicago Press.

Berque, J. (1973) Social structures of the High Atlas. Human Relations Area Files.

Besmer, F. E. (1983) Horses, musicians and gods: The Hausa cult of possession-trance. Bergin \& Garvey.

Bogoras, W. (1907) The Chukchee, part 2. - religion. E. J. Brill Ltd. and G. E. Stechert.

Bohannan, P., \& Bohannan, L. (1969) A source book on Tiv religion in 5 volumes. Human Relations Area Files.

Bollig, L. (1967) The inhabitants of the Truk Islands: religion, life and a short grammar of a Micronesian people. Human Relations Area Files.

Burling, R. (1963) Rengsanggri: Family and kinship in a Garo village. University of Pennsylvania Press.

Cerulli, E. (1959) Observations on the Moslem movement in Somaliland. Human Relations Area Files.

Chagnon, N. A. (1968) Yanomamö: The fierce people. Holt, Rinehart, and Winston.

Chapman, A. (1982) Drama and power in a bunting society: The Selk'nam of Tierra del Fuego. Cambridge University Press. 
Cipriani, L. (1961) Hygiene and medical practices among the Onge (Little Andaman). Anthropos 56:481-500. http://ehrafworldcultures.yale.edu/document?id=az02-006

Cohen, A. (1969) Custom E politics in urban Africa: A study of Hausa migrants in Yoruba towns. University of California Press.

Cohen, R. (1967) The Kanuri of Bornu. Holt, Rinehart, and Winston.

Colbacchini, A., \& Albisetti, C. (1996) The eastern Bororo Orarimogodogue of the eastern plateau of Mato Grosso. HRAF.

Damas, D. (1996) Culture summary: Copper Inuit. Human Relations Area Files.

De Laguna, F. (1972) Under Mount Saint Elias: The history and culture of the Yakutat Tlingit. Smithsonian Institution Press.

Debrunner, H. W. (1961) Witchcraft in Ghana: A study on the belief in destructive witches and its effect on the Akan tribes. Presbyterian Book Depot Ltd.

Diamond, N. (1969) K'un Shen: a Taiwan village. Holt, Rinehart, and Winston.

Ducey, P. R. (1956) Cultural continuity and population change on the Isle of Skye. Columbia University.

Early, J. D., \& Peters, J. F. (1990) The population dynamics of the Mucajai Yanomama. Academic Press.

Emmons, G. T., \& De Laguna, F. (1991) The Tlingit Indians Anthropological Papers of the American Museum of Natural History Vol. 70. University of Washington Press and the American Museum of Natural History. http://digitallibrary.amnh.org/handle/2246/253

Evans-Pritchard, E. E. (1937) Witchcraft, oracles, and magic among the Azande. Clarendon Press. Faulkingham, R. H. (1971) Political support in a Hausa village. Michigan State University.

Field, M. J. (1970) Search for security: An ethno-psychiatric study of rural Ghana. W. W. Norton \& Company.

Firth, R. (1939) Primitive Polynesian economy. George Routledge \& Sons.

Firth, R. (1954) The sociology of "magic" in Tikopia. Sociologus 4:97-116.

Firth, R. (1970) Rank and religion in Tikopia: A study in paganism and conversion to Christianity. Beacon Press.

Gallin, B. (1966) Hsin Hsing, Taiwan: A Chinese village in change. University of California Press.

Ganson, B. A. (1994) Better not take my manioc: Guarani religion, society, and politics in the Jesuit missions of Paraguay. University of Texas at Austin.

Gatschet, A. S. (1890) The Klamath Indians of southwestern Oregon. Government Printing Office. https://archive.org/details/klamathindiansof02gatsuoft

Geddes, A. (1955) The Isle of Lewis and Harris: A study in British community. Edinburgh University Press.

Gluckman, M. (1955) The judicial process among the Barotse of northern Rhodesia. The University of Manchester.

Godwin-Austen, H. H. (1872) On the stone monuments of the Khasi hill tribes, and of some of the peculiar rites and customs of the people. The Journal of the Anthropological Institute of Great Britain and Ireland 1:122-143.

Goldfrank, E. S. (1966) Changing configurations in the social organization of a Blackfoot tribe during the reserve period (the Blood of Alberta, Canada). University of Washington Press.

Goldman, I. (1963) The Cubeo: Indians of the Northwest Amazon. University of Illinois Press.

Goswami, M. C., \& Majudmar, D. N. (1968) A study of social attitudes among the Garo. Man in India 48:55-70. 
Graham, P. (1987) Iban shamanism: An analysis of the ethnographic literature. Department of Anthropology, Research School of Pacific Studies, the Australian National University. Greenberg, J. H. (1946) The influence of Islam on a Sudanese religion. J. J. Augustin. Griaule, M., \& Winchell, J. H. (1986) Dogon masks. Human Relations Area Files.

Gusinde, M. (1971) The Fireland Indians, vol. 1: The Selk'nam, on the life and thought of a hunting people of the Great Island of Tierra del Fuego. Human Relations Area Files.

Hanks, J. R. (1963) Maternity and its ritual in Bang Chan. Cornell University, Department of Asian Studies, Southeast Asia Program.

Harrell, S. (1974) Belief and unbelief in a Taiwan village. Stanford University.

Hatt, D. G. (1974) Skullcaps and turbans: Domestic authority and public leadership among the Idaw Tanan of the western High Atlas, Morocco. University of California, Los Angeles.

Helander, B. (1988) The slaughtered camel: Coping with fictitious descent among the Hubeer of southern Somalia. Uppsala University.

Herskovits, M. J. (1934) Rebel destiny: Among the bush Negroes of Dutch Guiana. Whittlesey House, McGraw-Hill Book Company.

Hocart, A. M. (1929) Lau Islands, Fiji. Bernice P. Bishop Museum.

Hoffman, B. G. (1967) The structure of traditional Moroccan rural society. Mouton \& Co.

Howe, J. (1986) The Kuna gathering: Contemporary village politics in Panama. University of Texas Press.

Human Relations Area Files (1967) The HRAF quality control sample universe. Behavior Science Notes 2:81-88.

Hunt, M. (1962) The dynamics of the domestic group in two Tzeltal villages: A contrastive comparison. University of Chicago.

Hutchinson, H. W. (1957) Village and plantation life in northeastern Brazil. University of Washington Press.

Irvine, J. T. (1973) Caste and communication in a Wolof village. University of Pennsylvania.

Itkonen, T. I. (1984) The Lapps in Finland up to 1945, vol. 2. Werner Söderström Osakeyhtiö. ehrafworldcultures.yale.edu/document?id=ep04-017

Jenness, D. (1922) The life of the Copper Eskimos. F. A. Acland.

Karsten, R. (1932) Indian tribes of the Argentine and Bolivian Chaco: Ethnological studies. Akademische Buchhandlung.

Kemp, P. (1935) Healing ritual: Studies in the technique and tradition of the southern Slavs. School of the Slavonic and East European Studies, University of London, Faber and Faber Limited.

Kennedy, J. G. (1978) Tarahumara of the Sierra Madre: Beer, ecology, and social organization. AHM Publishing.

Lagae, C. R. (1999) The Azande or Niam-Niam: Zande organizations, religious and magical beliefs, family customs. HRAF.

Lambrecht, F. (1955) The Mayawyaw ritual: VI. Illness and its ritual. Journal of East Asiatic Studies 4:1-155.

Lambrecht, F. (1957) The Mayawyaw ritual: VII. Hunting and its ritual. Journal of East Asiatic Studies 6:1-28.

Landes, R. (1937) Ojibwa sociology. Columbia University Press.

Landgraf, A. J. (2016) An introduction to the logisticPCA R package. https://cran.rproject.org/web/packages/logisticPCA/vignettes/logisticPCA.html. Accessed 11 July 2018 
Landgraf, A. J., \& Lee, Y. (2015) Dimensionality reduction for binary data through the projection of natural parameters arXiv preprint arXiv:1510.06112 .

Leach, E. R. (1961) Pul Eliya, a village in Ceylon: A study of land tenure and kinship. Cambridge University Press.

Lewis, I. M. (1961) A pastoral democracy: A study of pastoralism and politics among the northern Somali of the Horn of Africa. Oxford University Press.

Lewis, I. M. (1963) Dualism in Somali notions of power. The Journal of the Royal Anthropological Institute of Great Britain and Ireland 93:109-116.

MacDougall, R. D. (1971) Domestic architecture among the Kandyan Sinhalese. Cornell University. Mahony, F. J. (1971) A Trukese theory of medicine. University Microfilms.

Mair, L. P. (1934) An African people in the twentieth century. Routledge \& Songs.

Majudmar, D. N. (1978) A study of culture change in two Garo villages. Anthropological Survey of India, Government of India.

Malinowski, B. (1922) Argonauts of the western Pacific: An account of native enterprise and adventure in the archipelagoes of Melanesian Nerw Guinea. George Routledge \& Sons, Ltd.

Man, E. H. (1932) On the aboriginal inhabitants of the Andaman Islands. The Royal Anthropological Institute of Great Britain and Ireland.

Marak, K. R. (1997) Traditions and modernity in matrilineal tribal society. Inter-India Publications.

Marshall, D. S. (1950) Cuna folk: A conceptual scheme involving the dynamic factors of culture, as applied to the Cuna Indians of Darien. Harvard University.

Masters, W. M. (1953) Rowanduz: A Kurdish administrative and mercantile center. University of Michigan.

Maxwell, K. B. (1983) Bemba myth and ritual: The impact of literacy on an oral culture. P. Lang.

McCormack, A. P. (1964) Khasis. In: Ethnic Groups of mainland Southeast Asia eds. F. M. Lebar, G. C. Hickey, \& J. K. Musgrave, pp. 105-112. Human Relations Area Files.

McKim, F. (1947) San Blas: An account of the Cuna Indians of Panama; The forbidden land: Reconnaissance of upper Bayano River, R.P., in 1936: Two posthumous works. Etnografiska Museet.

Merker, M. (1971) The Masai: Ethnographic monograph of an East African Semite people. Human Relations Area Files.

Merrill, W. L. (1988) Rarámuri souls: Knowledge and social process in northern Mexico. Smithsonian Institution Press.

Messing, S. D. (1985) Highland plateau Ambara of Ethiopia. Human Relations Area Files.

Métraux, A. (1943) Suicide among the Matako of the Argentine Gran Chaco. América Indígena 3:199-210.

Métraux, A. (1959) Report on the ethnography of the Mataco Indians of the Argentine Gran Chaco. Human Relations Area Files.

Montagne, R. (1973) The Berbers and the Makbzen in the south of Morocco: Essay on the political transformation of the sedentary Berbers (the Chleuh group). Human Relations Area Files.

Murie, J. R. (1914) Pawnee Indian societies. Anthropological Papers of the American Museum of Natural History 9:543-644.

Naroll, R. (1967) The proposed HRAF probability sample. Behavior Science Notes 2:70-80. doi:10.4135/9781412953948

Nash, J. C. (1970) In the eyes of the ancestors: Belief and behavior in a Mayan community. Yale 
University Press.

Nordenskiöld, E. (1930) Picture-writings and other documents by Néle, Charles Slater, Charlie

Nelson and other Cuna Indians. Elanders Boktryckeri Aktiebolag.

Nordenskiöld, E. (1966) Miracle men and diviners among the Cuna Indians. Human Relations Area Files.

Nordenskiöld, E., \& Kantule, R. P. (1938) An historical and ethnological survey of the Cuna Indians. Göteborg Museum.

Orley, J. H. (1970) Culture and mental illness: A study from Uganda. The Makere Institute of Social Research and East African Publishing House.

Parker, A. C. (1913) The code of Handsome Lake, the Seneca prophet. University of the State of New York.

Parman, S. (1990) Scottish crofters: An historical ethnography of a Celtic village. Holt, Rinehart, and Winston.

Pavlovic, J. M. (1973) Folk life and customs in the Kragujevac region of the Jasenica in Sumdaija. Human Relations Area Files.

Peshkin, A. (1972) Kanuri schoolchildren: Education and social mobilization in Nigeria. Holt, Rinehart, and Winston.

Pierson, D. (1967) Negroes in Brazil. Southern Illinois University Press.

Pilz, A. (1988) Manang Jabing Anak Incham: A study of an Iban healer, Sarawak. D. Reimer.

Playfair, A. (1909) The Garos. David Nutt. https://archive.org/details/in.ernet.dli.2015.500276

Pospisil, L. J. (1958) Kapauku Papuans and their law. Yale University: Department of Anthropology.

Pospisil, L. J. (1978) The Kapauku Papuans of West Nerw Guinea. Holt, Rinehart, and Winston.

Price, R. (1990) Alabi's world. Johns Hopkins University Press.

Pryde, D. (1972) Nunaga: My land, my country. M. G. Hurtig Ltd.

R Core Team (2015) R: A language and environment for statistical computing. R Foundation for Statistical Computing. http://www.r-project.org/

Reichel-Dolmatoff, G. (1971) Amazonian cosmos: The sexual and religious symbolism of the Tukano Indians. University of Chicago Press.

Reminick, R. A. (1974) The evil eye belief among the Amhara of Ethiopia. Ethnology 13:279291.

Reynolds, B. (1963) Magic, divination and witchcraft among the Barotse of northern Rhodesia. Chatto and Windus.

Richards, A. I. (1935) A modern movement of witch-finders. Africa 8:448-461.

Rogers, E. S. (1962) The Round Lake Ojibwa. Ontario Department of Lands and Forests for the Royal Ontario Museum. https://archive.org/details/roundlakeojibwa00roge

Rongmuthu, D. S. (1960) The folk-tales of the Garos. University of Gauhati, Department of Publications.

Sandin, B. (1967) The Sea Dayaks of Borneo: Before White Rajah rule. MacMillan and Co.

Sandin, B. (1980) Iban adat and augury. Penerbit Universiti Sains Malaysia for School of Comparative Sciences.

Saso, M. R. (1974) Orthodoxy and heterodoxy in Taoist ritual. In: Religion and ritual in Chinese society ed. A. P. Wolf, pp. 325-336. Stanford University Press.

Schaden, E., \& Lewinsóhn, L.-P. (1969) Fundamental aspects of Guarani culture. Human Relations Area Files. 
Scheffer, J. (1704) The history of Lapland: Containing a geographical description, and a natural bistory of that country; with an account of the inhabitants, their original, religion, customs, habits, marriages, conjurations, employments, etc. Tho. Newborough, at the Golden-Ball in St. Paul's-Church-Yard and R. Parker under the Royal Exchange.

https://archive.org/details/historyoflapland00sche

Schultz, J. W. (1930) The sun god's children. Houghton Mifflin.

Seaman, G. (1981) The sexual politics of karmic retribution. In: The anthropology of Taiwanese society eds. E. M. Ahern \& H. Gates, pp. 381-396. Stanford University Press.

Selden, S. W. (1966) The legend, myth and Code of Deganawidah and their significance to Iroquois cultural history. Indiana University.

Sieroszewski, W. (1993) The Yakut: An experiment in ethnographic research. Human Relations Area Files.

Spencer, B., \& Gillen, F. J. (1927) The Arunta: A study of a Stone Age people. Macmillan and Co., Ltd.

Spencer, P. (1988) The Maasai of Matapato: A study of rituals of rebellion. Indiana University Press.

St. Johnston, T. R. (1918) The Lau Islands (Fiji) and their fairy tales and folk-lore. The Times Book Co.

Stefánsson, V. (1913) My life with the Eskimo. The Macmillan Co.

Stegmiller, P. F., \& Knight, E. (1956) The religious life of the Khasi. Human Relations Area Files.

Stern, T. (1965) The Klamath Tribe: A people and their reservation. University of Washington Press.

Sutlive, V. H. (1992) Tun Jugah of Sarawak: Colonialism and Iban response. In: . Fajar Bakti.

Talayesva, D. C., \& Simmons, L. W. (1942) Sun Chief: The autobiography of a Hopi Indian. Yale University Press.

Tambiah, S. J. (1983) On flying witches and flying canoes: The coding of male and female values. In: The Kula: New perspectives on Massim exchange eds. J. W. Leach \& E. Leach, pp. 171-200. Cambridge University Press.

Textor, R. B. (1973) Roster of the gods: An ethnography of the supernatural in a Thai village. Human Relations Area Files.

Tschopik, H. (1946) The Aymara. Smithsonian Institution.

Tschopik, H. (1951) The Aymara of Chucuito, Peru. 1, Magic. Anthropological Papers of the American Museum of Natural History 44:133-308.

Turnbull, C. M. (1965a) Wayward Servants: The Two Worlds of the African Pygmies. Natural History Press.

Turnbull, C. M. (1965b) The Mbuti Pygmies: An Ethnographic Survey Anthropological Papers of the American Museum of Natural History Vol. 50. The American Museum of Natural History.

van Beek, W. E. A. (1994) The innocent sorcerer: Coping with evil in two African societies (Kapsiki \& Dogon). In: Religion in Africa: Experience and expression eds. T. D. Blakely, W. E. A. van Beek, \& D. L. Thompson, pp. 196-228. James Currey.

Wafer, L. (1934) A new voyage and description of the Isthmus of America. Hakluyt Society.

Wallace, A. F. C. (1972) The death and rebirth of the Seneca. Vintage Books.

Weltfish, G. (1965) The lost universe: With a closing chapter on "The universe regained." Basic Books.

Wilbert, J. (1995) The Sanema. HRAF. 
Wolf, A. P., \& Huang, C. (1980) Marriage and adoption in China, 1845-1945. Stanford University Press. 